\title{
Inheritance Taxation and Wealth Effects on the Labor Supply of Heirs
}

\author{
Fabian Kindermann \\ University of Regensburg, \\ CEPR, Netspar, HCEO
}

\author{
Lukas Mayr \\ University of Essex
}

\author{
Dominik Sachs \\ University of Munich, CEPR and \\ CESifo
}

December 3, 2019

\begin{abstract}
The taxation of bequests can have a positive impact on the labor supply of heirs through wealth effects. This leads to an increase in labor income tax revenue on top of direct bequest tax revenue. We first show in a theoretical model that a simple back-of-the-envelope calculation, based on existing estimates for the reduction in earnings after wealth transfers, fails: the marginal propensity to earn out of unearned income is not a sufficient statistic for the calculation of this effect because (i) heirs anticipate the reduction in net bequests and adjust their labor supply already prior to inheriting, and (ii) when bequest receipt is stochastic, even those who ex post end up not inheriting anything respond ex ante to the implied change in their distribution of net bequests. We quantitatively elaborate the size of the overall revenue effect due to labor supply changes of heirs by using a state of the art life-cycle model that we calibrate to the German economy. Besides the joint distribution of income and inheritances, quasi-experimental evidence regarding the size of wealth effects on labor supply is a key target for this calibration. We find that for each Euro of bequest tax revenue the government mechanically generates, it obtains an additional 9 Cents of labor income tax revenue (in net present value) through higher labor supply of (non-)heirs.
\end{abstract}

\section{JEL Classifications: C68, D91, H22, H31, J22}

Keywords: bequests, taxation, life-cycle, labor-supply, dynamic scoring

We thank Alexander Gelber (the editor), three anonymous referees, Árpád Ábrahám, João Brogueira de Sousa, Raj Chetty, Ulrich Glogowsky, Piero Gottardi, Kristin Gunnarsson, Winfried Koeninger, Evi Pappa, Nicola Pavoni, James Poterba, Doina Radulescu, Markus Riegler, Stefan Staubli for comments that helped to substantially improve the paper. 


\section{Introduction}

Inheritances are of growing importance for Western economies. Using data from France, Piketty (2011) shows that since the 1950s the annual flow of inheritances has been ever increasing, so that in 2010 it amounted to roughly 15 percent of national income. He also predicts that this share could become as large as 25 percent in the mid 21st century. Following his theoretical arguments, it is quite likely that a similar (and potentially even stronger) trend should be observed in other countries with low economic and population growth such as Spain, Italy and Germany (Piketty, 2011, p.1077). This development clearly highlights the increasing potential of an inheritance tax in raising revenue. ${ }^{1}$

Despite the apparent importance of the topic, the incentive costs of inheritance taxation are not very well understood since clean empirical settings are rare (Kopczuk, 2013b). ${ }^{2}$ Furthermore, inheritance taxes are very unique in that they not only have incentive effects on those who give, but also on those who receive them. Hines (2013) substantiates these thoughts by stating that in addition to the typical income and substitution effects on bequeathers, inheritance taxes as well imply a wealth effect on the heirs. This wealth effect on heirs has been featured prominently in the so called Carnegie conjecture (Holtz-Eakin et al., 1993): Andrew Carnegie stated that "the parent who leaves his son enormous wealth generally deadens the talents and energies of the son, and tempts him to lead a less useful and less worthy life than he otherwise would" (Carnegie, 1891, p.371).

From a more scientific point of view, Kopczuk (2013a) has shown that this wealth effect on labor supply of the heirs plays an important role for the optimal level of the inheritance tax since it implies a fiscal externality: inheritance taxes increase earnings of the heirs which has a positive effect on government revenue if heirs face a positive marginal tax rate. In this paper we want to make progress in understanding exactly this fiscal externality. More specifically, we tackle the following policy question:

For each Euro of revenue raised directly through inheritance taxes, how much additional labor income tax revenue from heirs can the government expect to obtain?

Answering such a question purely empirically is problematic, because it is difficult to directly identify the impact of inheritances on the earnings of heirs. One reason for this is that inheritances can be (imperfectly) anticipated and therefore already shape

1 We use the terms bequest taxes and inheritance taxes interchangeably in this paper, albeit the fact that their effects might be different once an individual bequeathes to more than one heir and tax schedules are not proportional. For the experiments carried out in this paper, such a distinction, however, plays no role.

2 Wealth transfers "are infrequent (at the extreme, occurring just at death), thereby allowing for a long period of planning, making expectations about future tax policy critical and empirical identification of the effect of incentives particularly hard" (Kopczuk, 2013b, p.330). 
labor earnings prior to receipt. Furthermore, settings with exogenous variation in inheritances are rare. ${ }^{3}$ By contrast, there exists quasi-experimental evidence regarding the wealth effect of lottery gains on labor income (Imbens et al., 2001; Cesarini et al., 2017), which, owing to the small likelihood of their occurrence, can be regarded as exogenous. Our methodological approach consists in calibrating a version of the workhorse life-cycle model of the macroeconomics literature to be consistent with this quasi-experimental evidence on lottery gains and subsequently examining our policy question through the lens of this model.

As a theoretical warm-up, we first set up a simple three period model to analyze the tax revenue effects of a change in the bequest tax rate. We show that the marginal propensity to earn out of unearned income is not a sufficient statistic for the change in heirs' life-cycle labor supply (and therefore labor tax revenue), because an increase in the bequest tax is not an unanticipated reduction in wealth. Owing to anticipation, two effects arise on top of the simple standard wealth effect: (i) Individuals do form expectations about the inheritances they will receive and accordingly adjust their labor supply prior to receipt. (ii) If inheritances are stochastic, even individuals who did not inherit, but assigned a positive probability to receiving an inheritance, adjust their life-cycle labor supply.

We then study the quantitative importance of these effects in a state of the art lifecycle model. Our model features consumption, labor supply and savings decisions, heterogeneous labor productivity profiles and realistic expectations about the size and timing of bequests. We calibrate it to the German economy, with our most important target being the joint distribution of the size and timing of inheritances and labor earnings. To achieve credible magnitudes for the implied wealth effects, we target quasiexperimental evidence on wealth effects based on lottery gains (Cesarini et al., 2017). Specifically, we distribute lottery gains of different sizes among individuals of different ages in our model in the same way as they are distributed in the data set of Cesarini et al. (2017). We then calibrate preference parameters such that the impulse response of labor earnings generated by our model matches the empirical counterpart.

The only feature of our model, for which neither quasi-experimental evidence nor survey data provide us with clear guidance for calibration are expectations about the size of inheritances. Different assumptions on rational expectations can be consistent with the cross-sectional distribution of inheritances and earnings of heirs. We therefore consider a class of expectations that captures two special cases as polar outcomes: Conditional on the date at which the bequeather dies as well as the recipient's earnings (i) all individuals draw their inheritance from the empirical cross-sectional distribution, and (ii) all heirs know for sure how much they inherit. Besides these two polar cases, we consider linear combinations of the two that are all consistent with the cross-sectional joint distribution of inheritances and earnings of heirs.

3 There exists a small empirical literature on this issue to which we relate in the literature review below. 
Equipped with this quantitative model, we conduct the following policy experiment: We let the government levy a proportional tax of 1 percent on all bequests and calculate the resulting change in lifetime income and income tax payments for the total population of our model. For our benchmark calibration, we find that any Euro of bequests that is taken away from heirs increases their lifetime income by around 22 Cents in net present value, meaning discounted to the year of inheritance receipt. In terms of income tax payments this means that any Euro of revenue directly obtained through bequest taxes leads to additional tax revenues of around 9 cents (in net present value).

We decompose this number along two dimensions. First, we show that anticipation effects constitute approximately half of the total effect. This highlights the importance of considering a model with expectations and not only relying on a simple back-ofthe envelope calculation, where one would focus on post-inheritance earnings of heirs only. More generally, our approach quantifies the bias that would occur in an estimation which would focus solely on the labor supply changes of heirs after the receipt of an inheritance and would ignore anticipation effects as well as labor supply changes of non-heirs. Second, we consider heterogeneity in effects and answer our policy question for households of different earnings levels. We find that the effect of receiving an inheritance on individual labor earnings is increasing in earnings of heirs. This simply reflects the fact that lowering leisure by one hour is associated with a higher earnings gain for individuals with higher productivity.

Our policy implications are rather insensitive to the assumptions we make about how informed individuals are with respect to their inheritances. While this number increases slightly in the degree of information, it always remains between 8 and 10 Cents. In addition, we quantify how the assumption that agents rationally anticipate inheritances affects the results. We show that if agents were myopic, in the sense that they were completely surprised by the received inheritance, the government would generate 6 Cents in labor income tax revenue per Euro of bequest tax revenue, a reduction of the original effect by about one third. Overall, we conclude that the additional labor tax revenue collected from heirs is likely to be of sizable magnitude and should be taken into account in fiscal planning (dynamic scoring). ${ }^{4}$

The remainder of this paper is organized as follows. We first give a short overview over the related literature. In Section 2 we illustrate the main mechanisms within a tractable three-period model. In Section 3 we describe the full life-cycle model. We discuss our parameterization of expectations in Section 4. The calibration is explained in Section 5. In Section 6 we present our results and perform several robustness checks. Section 7 concludes.

Related Literature. The paper is related to and motivated by a small but growing quasi-experimental literature of wealth effects on labor supply. Imbens et al. (2001) is

4 To put this number into perspective, note that Saez et al. (2012) report the marginal excess burden per dollar of federal income tax raised to be below 20 cents. 
the first paper to use lottery data to estimate the impact of wealth on labor supply. They document that, on average, a one dollar wealth increase triggers a decrease in earnings of 11 Cents. Cesarini et al. (2017) use a similar setting in Sweden and obtain surprisingly similar numbers. Picchio et al. (2018) study lottery winners in the Netherlands. While they find no effects along the extensive margin, the impact along the intensive margin is a bit smaller than in Imbens et al. (2001) and Cesarini et al. (2017). Gelber et al. (2017) analyze the wealth effect for individuals who receive disability insurance. The individuals they consider receive around $\$ 1,700$ of DI benefits per month. The sample is particular in the sense that monthly income among the studied subjects is very low, on average around $\$ 200$ per month. The authors have a very clean identification strategy (regression-kink design) and find an income effect from one dollar of additional unearned income of about 20 Cents. $^{5}$

Further, our paper is related to the literature that estimates the impact of inheritances on the labor supply of heirs. Papers along these lines include Holtz-Eakin et al. (1993), who document the effect of bequests on labor force participation, and Brown et al. (2010), who investigate retirement choices. In a recent study Doorley and Pestel (2016) use the German Socio-Economic Panel (SOEP) to analyze the effect of inheritances on (actual and desired) hours worked, self-employment and hiring of entrepreneurs. The authors find that women who receive an inheritance reduce their labor supply by about 1.5 hours a week, while men's labor supply is by and large unaffected.

More relatedly, Elinder et al. (2012) examine the influence of inheritances on the earnings of heirs and use variation in the size of inheritances for identification. The sample they consider is very small, however. They do find effects on earnings that are significantly larger than the ones implied by our model. Bø et al. (2018) study the impact of bequests on labor earnings examining Norwegian administrative data with a propensity score matching approach. They find an effect that is roughly 50 percent below the one determined in our model. Yet, they only look at the labor supply reaction of heirs upon receipt of an inheritance and ignore anticipation effects. As shown in our quantitative analysis, the resulting bias from omitting anticipation effects can be expected to amount to roughly half of the total effect. Hence, the results in Bø et al. (2018) are by and large consistent with our findings.

A recent related public economics paper is Koeniger and Prat (2018), who analyze the policy implications of wealth effects from bequests. In a dynastic Mirrleesian environment, they find that such wealth effects create a force for less educational investment of children from wealthy families.

The fact that taxes on wealth have income effects on labor supply is, of course, not confined to inherited wealth. In a two-period lifecycle model with linear taxes, Jacobs and

5 Another recent related study is Bick et al. (2018), who document differences in hours worked across countries at different development stages. They find that both labor force participation (extensive margin) and hours worked conditional on employment (intensive margin) are lower in high income countries. This pattern is very much in line with wealth effects on labor supply. 
Schindler (2012) have emphasized the role of these wealth effects for optimal capital taxes. In the New Dynamic Public Finance literature, a famous result is the optimality to discourage savings at the margin (Golosov et al., 2003). The intuition is that introducing a small savings distortion has only a second-order loss on individual utility through the implied distortion of the intertemporal margin but it does have a firstorder benefit by relaxing the incentive-constraint due to wealth effects (Kocherlakota, 2010, p.56).

\section{A Three-Period Framework}

In this section, we study a sequence of models that are rich enough to capture the main mechanisms at work in our quantitative setup, but simple enough to be analytically tractable. We thereby strive to achieve two goals: We want to (i) connect the labor earnings reactions to changes in unearned income to the fundamental preference parameters of our model and (ii) illustrate the different reactions to a surprise transfer (like a lottery win) and a change in bequests or bequest taxes that is anticipated by households. The quantitative setup in Section 3 finally comes with several additional realistic features like household heterogeneity, progressive taxes and expectations about the size and timing of inheritances.

In Section 2.1, we start with a static model, in which a household has to choose consumption $c$ and labor supply $l$ so as to maximize the utility function

$$
u(c, l)=\frac{c^{1-\gamma}}{1-\gamma}-\frac{l^{1+\chi}}{1+\chi}
$$

where $\gamma$ is risk aversion and $\frac{1}{\chi}$ the Frisch elasticity of labor supply. ${ }^{6}$ The household receives net income from working as well as unearned income from either bequests ${ }^{7}$ or lump-sum transfers. In this static setup, where there is no role for intertemporal considerations, surprise transfers or changes in bequests trigger exactly the same labor earnings reaction, which is mainly a function of the preference parameters $\chi$ and $\gamma$, more specifically their ratio.

We then extend the model by allowing for a second period in Section 2.2. Bequests and surprise transfers are received in the first period, so that the household has to decide on how to spread the gains from rising unearned income over the two model periods.

6 The Propositions we derive in the following hold under more general utility functions as we show in Appendix A.3. Here we chose the same functional form as in our quantitative model in Section 3. Since Propositions 1 and 2 guide us in the calibration of the quantitative model, it is more instructive to understand the important parameters and their calibration targets already in this section. In an earlier version of this paper (Kindermann et al., 2018), we furthermore show that our central Proposition 3 also holds in a richer model.

7 Note that we treat bequests as an exogenous variable. 
In this setup, we show that the present value of the labor earnings reaction to a change in unearned income is, like in the static model, a function of the parameters $\chi$ and $\gamma$ and does not directly depend on the intertemporal discount factor. The discount factor, yet, governs how the earnings reaction is distributed between the two periods. A lower discount factor leads to a smaller labor earnings reaction in the first period of the model and a stronger reaction in the second, and vice versa.

Last but not least, in Section 2.3, we add a third period to the model, but this time prior to the receipt of inheritances. In this setup, expectations about the future play a crucial role. When a household receives an unanticipated transfer like a lottery win, her labor earnings reaction is identical to the one in the previous two period model. If, however, the household anticipates changes in bequests or bequest taxes prior to receipt, this shapes labor supply and savings even in the first period of the model. If bequests are probabilistic, this in turn also has an impact on households who ex post did not receive an inheritance.

\subsection{A Static Model}

In the static setup, a household maximizes utility given in (1) subject to the budget constraint

$$
c \leq(1-\tau) y+\underbrace{\left(1-\tau_{b}\right) b+T}_{=: R} .
$$

The agent receives gross income $y=w l$ from working $l$ hours at wage $w$ and has to pay a proportional labor earnings tax $\tau$. In addition to net earnings, there are two sources of unearned income $R$ : after-tax bequests $\left(1-\tau_{b}\right) b$ as well us lump-sum transfer $T$.

It is straightforward to see that any change in unearned income $R$ - might it be through a change in $\tau_{b}, b$ or $T$ - triggers a labor earnings reaction, which can be summarized in the statistic

$$
\eta=\frac{d y}{d R}=-\frac{1}{\left(1+\frac{\chi}{\gamma}\right)(1-\tau)+\frac{\chi}{\gamma} \frac{R}{y}} \leq 0,
$$

see Appendix A.1. Hence, a one Euro increase in unearned income leads to a change in household labor earnings of $\eta$ Euros. The above equation shows that the most important determinant of the labor earnings reaction to a change in unearned income is the ratio of preference parameters $\frac{\chi}{\gamma}$. Any combination of risk aversion $\gamma$ and the Frisch elasticity of labor supply $\frac{1}{\chi}$ that ensures a constant ratio will lead to the same labor earnings reaction. 


\subsection{Impulse Responses and Intertemporal Labor Supply}

The static model is a useful benchmark, as it allows us to study labor earnings reactions without caring about issues of timing. In a more realistic setup, however, there is more than one period over which the household can decide to spread the gains from an increase in unearned income. As a result, a change in bequests or transfers will trigger a dynamic response in labor earnings in all subsequent periods. To shed some light on the determinants of the overall labor earnings reaction as well as on the shape of the impulse response, we extend our model by a second period.

Households maximize the intertemporal utility function

$$
U=u\left(c_{1}, l_{1}\right)+\beta u\left(c_{2}, l_{2}\right),
$$

where subscripts indicate model periods. Instantaneous preferences are the same as in the static model and $\beta$ denotes a time discount factor. The intertemporal budget constraint of the household reads

$$
c_{1}+\frac{c_{2}}{1+r} \leq(1-\tau)[\underbrace{y_{1}+\frac{y_{2}}{1+r}}_{=: y}]+\underbrace{\left(1-\tau_{b}\right) b+T_{1}+\frac{T_{2}}{1+r}}_{=: R},
$$

where we let $y$ be the present value of labor earnings and $R$ the present value of unearned income. To calculate present value terms, we discount second period values with the interest rate $r$. Note that by making these present value definitions, the budget constraint of the household looks very similar to the one in the static model setup. In fact, one can show that the total labor supply reaction does as well.

Proposition 1 (Present Value of Labor Earnings) An increase in the present value of exogenous income $R$ triggers an overall labor earnings response of

$$
\eta=\frac{d y}{d R}=\frac{d y_{1}+\frac{d y_{2}}{1+r}}{d R}=-\frac{1}{\left(1+\frac{\chi}{\gamma}\right)(1-\tau)+\frac{\chi}{\gamma} \frac{R}{y}} \leq 0
$$

Proof: see Appendix A.2.

Proposition 1 tells us that, in present value terms, the labor earnings reactions in the static and the dynamic model have exactly the same determinants. Most importantly, the major determinants of the reaction are the net-of-tax rate $1-\tau$ as well as the ratio of elasticities $\frac{\chi}{\gamma}$. The discount factor, on the other hand, plays only a minor role and affects $\eta$ at most indirectly through the present value of earnings $y$ itself. If a higher discount factor leads to a larger (smaller) present value of earnings, the present value earnings reaction to changes in exogenous income would increase (fall). While the discount factor has only a minor impact on the overall earnings response, it affects the impulse response function, as the following proposition shows. 
Proposition 2 (Impulse Response) Let us define the within-period changes in labor earnings to a change in unearned income as

$$
\eta_{1}=\frac{d y_{1}}{d R} \quad \text { and } \quad \eta_{2}=\frac{d y_{2}}{d R} \quad \text { such that } \quad \eta=\eta_{1}+\frac{\eta_{2}}{1+r} .
$$

Then, we have

$$
\eta_{2}=\left[\frac{w_{2}}{w_{1}}\right]^{1+\frac{1}{\chi}}[\beta(1+r)]^{-\frac{1}{\chi}} \eta_{1}=\frac{y_{2}}{y_{1}} \eta_{1} .
$$

Proof: see Appendix A.2.

The proposition states that the intertemporal earnings reaction to a change in exogenous income is proportional to relative incomes $\frac{y_{2}}{y_{1}}$. The income ratio $\frac{y_{2}}{y_{1}}$, in turn, is directly shaped by the discount factor $\beta$. If individuals discount the future more heavily, they do not care so much about the disutility of labor in the second period relative to the first period. Hence, they will choose a higher labor supply and therefore labor earnings in period 2, which in turn means that variations in unearned income are to a larger extent absorbed by labor supply adjustments in the second period.

As shown in the above propositions, the discount factor mainly governs how agents distribute their earnings response between periods, while the overall response is predominantly driven by how elastic labor supply is relative to consumption (the ratio $\gamma / \chi)$. Our choice of preferences features constant elasticities of substitution both between intertemporal allocations as well as between consumption and labor within a given period. As a result, the percentage changes in labor earnings between both periods as well as the percentage changes between consumption and earnings in each period are proportional. Particularly, their proportion depends on the respective elasticities of consumption and labor supply. For our choice of preferences, this means that

$$
\frac{d c_{i}}{c_{i}}=\frac{\chi}{\gamma} \frac{d y_{i}}{y_{i}} \quad \text { and } \quad \frac{d y_{2}}{y_{2}}=\frac{\chi}{\chi} \frac{d y_{1}}{y_{1}}=\frac{d y_{1}}{y_{1}} .
$$

From the second relation, we directly obtain Proposition 2. These relations together with the intertemporal budget constraint furthermore imply Proposition 1.8

The results of the above propositions have implications for the calibration of our quantitative life-cycle model, which we discuss in Section 5. In order to determine the ratio $\frac{\chi}{\gamma}$, it is best to look at the present value reaction of labor earnings towards changes in unearned income. Yet, in order to pin down a suitable combination of risk aversion

8 In Appendix A.3 we derive the impulse response in labor earnings without imposing a functional form on preferences. In fact, the only restriction we impose is that preferences are time-separable. We show that the property of proportional percentage changes across both periods' consumption and labor earnings extends to all preferences that feature time-invariant elasticities. As a consequence, the qualitative properties in Propositions 1 and 2 also carry over to this more general set of preferences. 
$\gamma$, the inverse of the Frisch elasticity of labor supply $\chi$, and the time discount factor $\beta$, we need detailed information on the intertemporal shape of the earnings reaction, the impulse response function. In turn, this means that once we fix some value of $\chi$, we can pin down $\gamma$ and $\beta$ by targeting the present value labor earnings reaction and the impulse response function, respectively.

\subsection{Anticipation Effects: Inheritances vs. Lottery Wins}

So far, we only studied individuals who knew for sure that they receive unearned income and that this income changes. In the context of bequests, however, we have to put more effort into thinking about expectations and anticipation effects that might affect behavior prior to the receipt of an unearned income transfer. We therefore add another period to our model, at date 0 , in which households again have to decide about consumption, labor supply and savings and form expectations about future transfers as well as their changes.

We assume that a fraction $\pi$ of households receives an inheritance $b$ at date $t=1$, and that households have no information about whether they will receive a bequest or not. Hence, making rational forecasts, households maximize expected utility

$$
u\left(c_{0}, l_{0}\right)+\beta\left[\pi\left(u\left(c_{1}^{I}, l_{1}^{I}\right)+\beta u\left(c_{2}^{I}, l_{2}^{I}\right)\right)+(1-\pi)\left(u\left(c_{1}^{N}, l_{1}^{N}\right)+\beta u\left(c_{2}^{N}, l_{2}^{N}\right)\right)\right],
$$

where superscripts $I$ and $N$ denote the cases in which the household does and does not receive an inheritance in period 1 , respectively.

The budget constraint of the household in period 0 reads

$$
c_{0} \leq(1-\tau) y_{0}+\underbrace{T_{0}-a_{1}}_{=: R_{0}} .
$$

In period 0 , households generate income from working $y_{0}$ and transfers $T_{0}$ in order to consume $c_{0}$ or save into the next period $a_{1}$. In the previous section, we did not explicitly look at the savings response of the household to a change in unearned income, since the model had no uncertainty. Hence, it was easy to solve the labor supply response in closed form, implicitly understanding that households adjust savings in order to distribute the gains or losses from a change in unearned income over several periods. In this section, however, there is uncertainty about the size of future transfers, which makes it impossible to explicitly solve for the full intertemporal earnings reaction. Hence, we for now treat the savings reaction in period 0 as a separate object and discuss its sign later on. We define $R_{0}$ as non-labor resources in period 0 , which this time could also be negative. Note that including first-period savings into the definition implies that $R_{0}$ now has an endogenous component, in contrast to the previous setups, where $R$ was completely exogenous. We can then write

$$
\eta_{0}=\left.\frac{d y_{0}}{d R_{0}}\right|_{d a_{1}=0}=-\frac{1}{\left(1+\frac{\chi}{\gamma}\right)(1-\tau)+\frac{\chi}{\gamma} \frac{R_{0}}{y_{0}}},
$$


see Appendix A.4. $\eta_{0}$ is the response of labor earnings to an increase in unearned income under the assumption that savings are not adjusted.

It is important to note that the household problem in periods 1 and 2 is identical to the problem in Section $2.2,{ }^{9}$ with the only difference that the definition of unearned income $R^{K}$ has changed. On the one hand, unearned income only contains net payments from bequests whenever the household is actually an heir $(K=I)$. On the other hand, purely from the perspective of periods 1 and 2, savings that were formed in period 0 also count as a source of unearned income. Consequently, for all $K=I, N$, we can write the present value budget constraint as

$$
c_{1}^{K}+\frac{c_{2}^{K}}{1+r} \leq(1-\tau)[\underbrace{y_{1}^{K}+\frac{y_{2}^{K}}{1+r}}_{y^{K}}]+\underbrace{\mathbb{1}_{K=I}\left(1-\tau_{b}\right) b+T_{1}+\frac{T_{2}}{1+r}+(1+r) a_{1}}_{=: R^{K}} .
$$

With the knowledge of the previous section, we immediately obtain

$$
\eta^{K}=\frac{d y^{K}}{d R^{K}}=-\frac{1}{\left(1+\frac{\chi}{\gamma}\right)(1-\tau)+\frac{\chi}{\gamma} \frac{R^{K}}{y^{K}}} .
$$

What is the important lesson to learn from these considerations? In order to understand how labor earnings react to changes in bequests or bequest taxes, we only have to understand how the unearned income components $R_{0}$ and $R^{K}$ are influenced by the change in inheritances. When bequest taxes are rationally anticipated by households, they will react to the change in legislation with their savings behavior even prior to the receipt of an inheritance, which is stated in the following proposition.

Proposition 3 (Anticipated bequests) Assume that the tax rate on bequests is changed and that households perfectly foresee this change in taxes. Denote by $\alpha=\frac{d a_{1}}{d \tau_{b}} \frac{1}{b}$ the savings response of the household in period 0 to the change in the bequest tax rate. Then we have

$$
\frac{d R_{0}}{d \tau_{b}} \frac{1}{b}=-\alpha \quad, \quad \frac{d R^{N}}{d \tau_{b}} \frac{1}{b}=(1+r) \alpha \quad \text { and } \quad \frac{d R^{I}}{d \tau_{b}} \frac{1}{b}=-1+(1+r) \alpha
$$

As a result, we obtain

$$
\begin{aligned}
\frac{d y_{0}}{d \tau_{b}} \frac{1}{b}=-\eta_{0} \alpha, & \frac{d y^{N}}{d \tau_{b}} \frac{1}{b}=\eta^{N}(1+r) \alpha \text { and } \\
\frac{d y^{I}}{d \tau_{b}} \frac{1}{b} & =\eta^{I}[-1+(1+r) \alpha] .
\end{aligned}
$$

In expected present value terms this means that

$$
\frac{d y}{d \tau_{b}} \frac{1}{b}:=\frac{d y_{0}+\pi \frac{d y^{I}}{1+r}+(1-\pi) \frac{d y^{I} N}{1+r}}{d \tau_{b}} \frac{1}{b}=\underbrace{-\frac{\pi \eta^{I}}{1+r}}_{\text {naive effect }} \underbrace{-\alpha\left[\eta_{0}-\left(\pi \eta^{I}+(1-\pi) \eta^{N}\right)\right]}_{\text {effect of savings adjustment }}
$$

9 We therefore use a quite similar notation as in the previous model. 


$$
=\underbrace{-\alpha \eta_{0}}_{\text {anticipation effect }}+\underbrace{\pi \eta^{I}\left[\alpha-\frac{1}{1+r}\right]}_{\text {heir effect }}+\underbrace{(1-\pi) \eta^{N} \alpha}_{\text {non-heir effect }}
$$

Proof: see Appendix A.4.

Proposition 3 shows that an anticipated change in bequest taxes does not only influence the labor earnings of heirs. As households adjust their savings to the change in taxes already in period 0 , there will be a labor earnings reaction already prior to the receipt of inheritances, which we call the anticipation effect. This also implies that the adjustment in savings has an impact on those who ex post turn out not to have received an inheritance $(K=N)$. We call this the non-heir effect.

Proposition 3 also sheds light on the case in which bequest tax changes come at a surprise for all households, like a lottery win. In such a case, agents are not able to react to the change in taxes in period 0 , prior to the receipt of the inheritance. Consequently, the savings effect would be $\alpha=0$ and consequently $\frac{d y}{d \tau_{b}} \frac{1}{b}=\frac{-\pi \eta^{I}}{1+r}$. This shows that in this case we could deliberately do a back-of-the-envelope calculation using evidence on the wealth effects of lottery gains, and thereby obtain valid results.

Summing up, the present value labor earnings reaction to an anticipated change in bequest taxes is not only composed of the "naive" wealth effect $\eta_{2}$, but it has an additional component

$$
-\alpha\left[\eta_{0}-\left(\pi \eta^{I}+(1-\pi) \eta^{N}\right)\right]
$$

Whether this component amplifies or dampens the overall earnings change depends on the magnitude of the savings effect as well as on the wealth effects on labor earnings at different stages of the life cycle. In Appendix A.4, we show that $\alpha \geq 0$. This makes sense intuitively, as an increase in bequest taxes lowers expected unearned income in period 1. In order to compensate for the shortfall in resources, the household will save some more resources in period 0 . Whether the term in square brackets is positive or negative depends on whether wealth effects are more pronounced towards the beginning or the end of a household's working life. In general, we would expect that wealth effects of labor earnings are small later in life, when households have already built up a stock of life-cycle savings and (in expectation) receive bequest. As a result, the term in square brackets in the above product would be positive and the anticipation effect would amplify the labor earnings reaction to changes in bequest taxes above the "naive" wealth effect. But there might be forces working against this view, like increasing wage profiles or progressive taxation.

In light of these results, we now want to employ a quantitative model, which brings several additional important and realistic features of a household's life cycle to the table. We use this model to analyze the total effect of bequest taxes on labor earnings and decompose the result into the anticipation effect and the post receipt effects on 
heirs and non-heirs. Our model suggests that the anticipation effect is substantial, accounting for almost half of the total effect in our preferred parameterization.

\section{Quantitative Life-Cycle Model}

Our previous theoretical analysis has revealed that the anticipation of bequests plays a crucial role in determining the labor supply response to a change in bequest taxes. In the following sections we construct and calibrate a full life-cycle model, which allows us to realistically quantify the effect of a change in bequest taxes on the labor supply of heirs.

Timing and endowments Time $t \in\{1, \ldots, T\}$ is discrete and period length is one year. The economy is populated by a continuum of mass one of heterogeneous households. Households enter the economy at age 20 (model age $t=1$ ). At this point in time, they are endowed with an earnings ability level $e \in\{1, \ldots, E\}$ and a signal $s \in\{0, \ldots, n\}$ about the amount of inheritance they might receive. Agents work until they reach the (exogenous) retirement age $t_{r}$. They die with certainty at age $T$.

Bequest and expectations Throughout their life-cycle, households might receive a bequest. Bequests are stochastic both with respect to timing and size. We assume that a household can only inherit once in her lifetime - at the age at which her ancestors pass away. Denote by $\left\{p_{t}^{e}\right\}_{t=1}^{T}$ the unconditional probability distribution of ancestors passing away when a household of ability $e$ is of age $t$. We assume that the chance of parents surviving their children is zero, i.e. $\sum_{t=1}^{T} p_{t}^{e}=1$.

When a household's parents die at time $t$, their bequest can take one of $n+1$ different levels $\left\{b_{i t}^{e}\right\}_{i=0}^{n}$, where $b_{0 t}^{e}=0$. We call $i \in\{0, \ldots, n\}$ a bequest class and assume that the conditional probability of the household's inheritance falling into such a class is time invariant. Agents form expectations about the class their inheritance will belong to according to the signal $s$ they received at the beginning of their life cycle. A signal of perfect quality would imply that a household falls into inheritance class $i=s$ with certainty. However, even if the heir knows her inheritance class with certainty, the size of the inheritance is uncertain in the sense that it depends on the time, at which she inherits (or the age of the parent at death). We will also consider less precise signals and will be more specific about how we formalize the quality of the signal in the next section. For now, we just denote by $\pi_{i s}^{e}$ the time invariant probability that a household with signal $s$ and earnings capacity $e$ attaches to receiving an inheritance of class $i$. The probability that an individual of type $(e, s)$ receives a bequest at age $t$ that falls into class $i$ is then given by $p_{t}^{e} \pi_{i s}^{e}$.

While the probability distribution over bequest classes $i$ is time invariant, bequest levels $b_{i t}^{e}$ in each class are allowed to vary over time $t$. This reflects, for example, that ancestors might run down their wealth throughout a prolonged retirement phase. Furthermore, the bequest levels $b_{i t}^{e}$ depend on the individual earnings capacity $e$, which 
provides more flexibility in matching the empirical correlation between earnings and bequests received.

Preferences At any age $t$, households decide about how much to consume $c_{t}$, how much to work $l_{t}$ and how much to save $a_{t}$. They have preferences over consumption and labor supply

$$
U_{0}(e, s)=\mathbb{E}\left[\sum_{t=1}^{T} \beta^{t-1}\left(\frac{c_{t}^{1-\gamma}}{1-\gamma}-\frac{l_{t}^{1+\chi}}{1+\chi}\right) \mid e, s\right]
$$

and form expectations about inheritances according to the above probabilities. We assume utility of consumption and disutility of labor to be additively separable. The parameter $\chi$ denotes the inverse of the Frisch elasticity of labor supply, $\beta$ is the time discount factor, and $\gamma$ is risk aversion.

Budget constraint The budget constraint is given by

$$
c_{t}+a_{t+1}=w_{t}^{e} l_{t}-\mathcal{T}\left(w_{t}^{e} l_{t}\right)+\mathcal{P}_{t}^{e}+W_{t}
$$

Consumption and savings into the next period are financed out of gross labor income $w_{t}^{e} l_{t}$ minus taxes $\mathcal{T}\left(w_{t}^{e} l_{t}\right)$, pension income $\mathcal{P}_{t}^{e}$ and wealth $W_{t}$. Gross labor income is the product of the wage rate $w_{t}^{e}$ and labor effort $l_{t}$. The function $\mathcal{T}($.$) maps gross labor$ income into a tax payment and is specified in more detail in the calibration section of this paper. Throughout retirement, the household receives pension income $\mathcal{P}_{t}^{e}$, which we assume to be constant and conditional on the household's earnings capacity. ${ }^{10}$ In particular, we set

$$
\mathcal{P}_{t}^{e}= \begin{cases}0 & \text { if } t<t_{r} \\ \mathcal{P}^{e}>0 & \text { if } t \geq t_{r}\end{cases}
$$

If the agent does not inherit at period $t$, her beginning-of-period-wealth is simply given by her savings including interest payments, i.e. $W_{t}=(1+r) a_{t}$, where $r$ is the interest rate on savings. If she does inherit, it also includes net bequests, i.e. $W_{t}=(1+r) a_{t}+$ $\left(1-\tau_{b}\right) b_{i t}^{e}$, where $\tau_{b}$ is the bequest tax rate.

Finally, throughout her economic life, an agent cannot accumulate debt beyond a minimal asset level $a_{\min } \in(-\infty, 0]$. In addition, she has to repay any outstanding debt before death. Hence the household's assets need to satisfy ${ }^{11}$

$$
a_{t} \geq a_{\min } \quad \text { as well as } \quad a_{T} \geq 0
$$

10 It turns out that the variance in labor earnings across earnings categories is by an order of magnitude higher than the variance within earnings categories. Hence, this is not a restrictive assumption.

11 Note that with $a_{\min }=-\infty$ these two equations are equivalent to the natural borrowing limit, i.e. in this case the household can borrow up to the amount that she can pay back with certainty (as long as she adjusts consumption accordingly). We will hence refer to the case $a_{\min }=-\infty$ as the "natural borrowing limit case". 
Retirement at age $t_{r}$ is mandatory. Hence labor supply needs to satisfy

$$
l_{t}=0 \quad \text { for all } \quad t \geq t_{r} .
$$

Dynamic optimization problem The state space of the household optimization problem contains the individual's earnings capacity $e$, the signal about the size of bequests $s$ as well as wealth $W_{t}$. Since households only inherit once in their life time, the state space further contains an indicator $h_{t} \in\{0,1\}$ for whether the agent's parents already passed away prior to or at date $t$. The dynamic optimization problem of the household hence reads

$$
V_{t}\left(e, s, h_{t}, W_{t}\right)=\max _{c_{t}, l_{t}, a_{t+1}}\left\{\frac{c_{t}^{1-\gamma}}{1-\gamma}-\frac{l_{t}^{1+\chi}}{1+\chi}+\beta \mathbb{E}\left[V_{t+1}\left(e, s, h_{t+1}, W_{t+1}\right) \mid e, s, h_{t}\right]\right\}
$$

subject to (7) and (8). If the household's parents are still alive, expectations are formed according to

$$
\begin{aligned}
& \mathbb{E}\left[V_{t+1}\left(e, s, h_{t+1}, W_{t+1}\right) \mid e, s, h_{t}=0\right] \\
&=\tilde{p}_{t+1}^{e} \sum_{i=0}^{n} \pi_{i s}^{e} V_{t+1}\left(e, s, 1,(1+r) a_{t+1}+\left(1-\tau_{b}\right) b_{i, t+1}^{e}\right) \\
&+\left[1-\tilde{p}_{t+1}^{e}\right] V_{t+1}\left(e, s, 0,(1+r) a_{t+1}\right) .
\end{aligned}
$$

Furthermore,

$$
\tilde{p}_{t+1}^{e}=\frac{p_{t+1}^{e}}{1-\sum_{s=1}^{t} p_{s}^{e}}
$$

is the conditional probability of receiving an inheritance at age $t+1$, given that one hasn't received an inheritance yet. In case the agent's ancestors already deceased, all uncertainty has been revealed and we can simply write

$$
\mathbb{E}\left[V_{t+1}\left(e, s, h_{t+1}, W_{t+1}\right) \mid e, s, h_{t}=1\right]=V_{t+1}\left(e, s, 1, W_{t+1}\right) .
$$

\section{Parameterizing expectations about bequests}

One important element of our life cycle model is the probability distribution $\pi_{i s}^{e}$ according to which a household forms expectations about the class $i$ her inheritance can fall into, including the case where no inheritance is received $i=0 .{ }^{12}$ Measuring expectations about inheritances is complicated if one can only observe actual cases of inheritances. Whereas our data allow us to estimate the distribution of inheritances

12 Note that the level of inheritance depends on the age at which the heir inherits even within a certain inheritance class. See Figure 3 and accompanying explanations. 
conditional on age and earnings of the heirs, this does not inform us about the expectations, which heirs in that age-earnings class actually had. We therefore suggest different parameterizations of the signal quality. We only require that they are all consistent with the conditional cross-sectional distribution of inheritances. On the one extreme, we will consider signals of perfect quality: conditional on the parents dying, heirs know for sure how much they inherit. On the other extreme, the signal contains no information at all: heirs just draw their inheritance from the estimated cross-sectional distribution. To elaborate how our results depend on expectations, we consider both extreme cases as well as intermediate ones.

More formally, the signal $s \in\{0, \ldots, n\}$ an agent receives is a discrete number that contains information about which class $i$ her inheritance will fall into. The parameter $\sigma \in[0,1]$ is an indicator for the quality of this signal. If $\sigma=0$, the signal contains no information at all, while for $\sigma=1$ the household knows with certainty that $i=s$. At the beginning of the life cycle, a fraction $\varphi_{s}^{e}$ of households of ability $e$ is equipped with the signal $s$. We now have to make a distinction between the individual specific probability distribution $\pi_{i s^{\prime}}^{e}$, which depends on the individual signal $s$, as well as the population wide (cross-sectional) distribution $\omega_{i}^{e}$ of households of earnings class $e$ over different bequest levels $i$. In order for the individual probability distributions to be consistent with the cross-sectional distribution, we require

$$
\forall i, e: \sum_{s=0}^{n} \varphi_{s}^{e} \pi_{i s}^{e}=\omega_{i}^{e}
$$

Note that when the signal is fully informative about the household's bequest class $(\sigma=1)$, the individual probability distribution is

$$
\pi_{i s}^{e}= \begin{cases}1 & \text { if } i=s \text { and } \\ 0 & \text { otherwise. }\end{cases}
$$

On the other hand, if the signal contains no information $(\sigma=0)$, the best forecast a household can make about the class her inheritance will fall into is the cross-sectional distribution over all households of the same earnings level $\omega_{i}^{e}$, meaning that $\pi_{i s}^{e}=\omega_{i}^{e}$ for all $s=0, \ldots, n$. For any intermediate signal quality, we let the individual probability distribution be a convex combination of the two. Hence, we have

$$
\pi_{i s}^{e}=(1-\sigma) \omega_{i}^{e}+\sigma \mathbb{1}(i=s) \quad \text { for } \quad \sigma \in[0,1]
$$

where $\mathbb{1}(i=s)$ is an indicator function that takes a value of 1 if $i$ is equal to $s$ and 0 otherwise. For any $\sigma>0$, equation (9) directly implies

$$
\sum_{s=0}^{n} \varphi_{s}^{e}\left[(1-\sigma) \omega_{i}^{e}+\sigma \mathbb{1}(i=s)\right]=(1-\sigma) \omega_{i}^{e}+\sigma \varphi_{i}^{e} \stackrel{!}{=} \omega_{i}^{e}
$$

and therefore $\varphi_{i}^{e}=\omega_{i}^{e}$. Consequently, under rational expectations and for our choice of $\pi_{i s}^{e}$, the distribution of the population of an earnings level $e$ over different signals $s$ has to exactly equal the cross-sectional distribution of this population over inheritance levels $i$. 


\section{Calibration}

We calibrate our model in three steps:

1. We first estimate labor earnings profiles $y_{t}^{e}=w_{t}^{e} l_{t}$, the probability of ancestral death $p_{t}^{e}$, and the cross-sectional distribution of bequests $b_{i t}^{e}$ using data from the German Socio-Economic Panel (GSOEP).

2. In a second step, we parameterize further model parameters, prices and government policies.

3. Finally, we jointly pin down the labor supply elasticity parameter $\chi$, risk aversion $\gamma$ and the time discount factor $\beta$ such that our model is consistent with recent empirical evidence on the effects of lottery wins on labor earnings provided in Cesarini et al. (2017).

\subsection{Labor earnings and bequests}

Our main data source is the GSOEP, an annual panel survey on German households. ${ }^{13}$ We use data on age, education, labor income and inheritances on the household level in the years between 2000 and 2014, and - in order to have a large enough sample - pool together all data from these 15 different waves into one cross-section. ${ }^{14}$ We assume that a household consists of either one or two persons, meaning that we abstract from the presence of children or any other relative or non-relative household members. For two person households we identify the household head as the primary earner and use the head's age and education level in all further calculations. We define household labor income as the sum of labor earnings, public transfers (such as social assistance) and pension payments. In addition to age, GSOEP provides data on whether the household has received an inheritance in a respective survey year and if yes, about its size. To account for different household sizes, we divide gross labor income and inheritances of two person households by 1.5 , which equals the common scale parameter used by the OECD. Finally, we drop all observations for which information on either age, education level, labor income or inheritances are missing as well as all households aged 19 and below. This leaves us with a total of 163,369 observations.

\subsubsection{Labor earnings classes}

We define a total of $E=8$ different earnings classes, which result as a combination from two education levels and four income quartiles for each education level. We first

13 For detailed information about the GSOEP, see Wagner et al. (2007).

14 Note that we can not use data on the individual level, as the household is the only unit on which inheritance data can be observed in the GSOEP. Note that we adjust labor income and inheritance data using the CPI. 
stratify our sample according to the education level of the household. We say that a household has a low education, if the highest educational degree of the household head is a secondary or lower degree according to the ISCED97 education classification standard. All households with household head holding a tertiary education degree are considered highly educated. We assign households with low education into earnings classes $e=1,2,3,4$ and those with high education into $e=5,6,7,8$. We then group all households of an education level according to five year age bins, that is 20-24, 25$29, \ldots, 60-64$, and pool all observations aged 65 and above into one bin. Within each education-age group, we separate households into four quartiles according to their labor income, leading to 4 earnings classes within each educational group. Table 6 in Appendix $C$ summarizes mean earnings of the 8 earnings classes at different ages derived from the GSOEP. The last row of this table shows the shares of households in each earnings class in the total population. This shows that in our sample 28.4 percent of household heads hold a higher education degree.

In order to feed our model with annual data, we fit polynomials of the form

$$
y_{t}^{e}=\exp \left(\kappa_{0}^{e}+\kappa_{1}^{e} t+\kappa_{2}^{e} t^{2}+\kappa_{3}^{e} t^{3}+\kappa_{4}^{e} t^{4}\right)
$$

for each earnings class $e$ to our data. We derive the polynomial coefficients by minimizing a simple residual sum of squares between the data reported in Table 6 and the corresponding moments derived from the polynomial. Figure 1 shows the resulting age-earnings profiles.

Figure 1: Estimated age-earnings profiles for different earnings classes
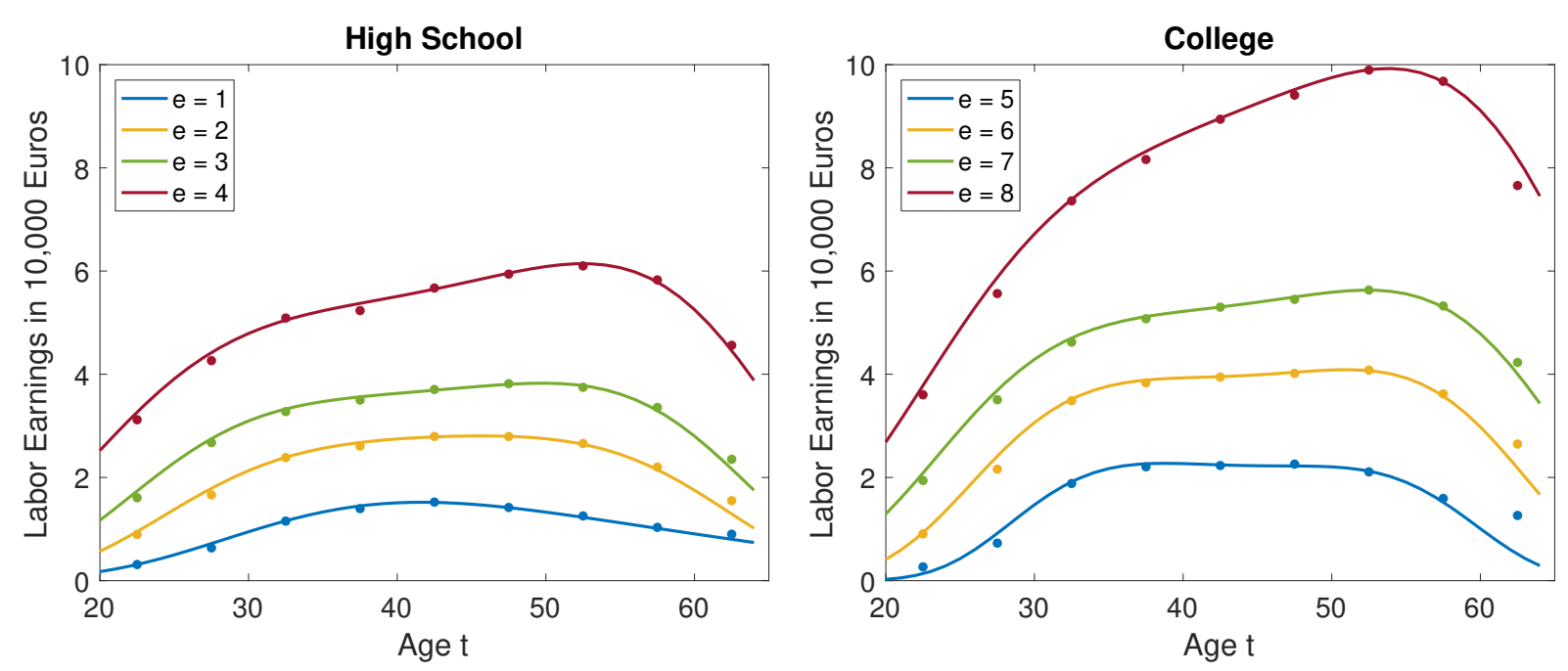

Our model features endogenous labor supply decisions. Hence, labor earnings - the product of labor effort $l_{t}$ and productivity $w_{t}^{e}-$ are an endogenous object. In order to back out labor productivity profiles that lead to the labor earnings profiles shown in Figure 1, we follow a dynamic version of the strategy proposed by Saez (2001), which we briefly outline in Appendix D. 


\subsubsection{Probabilities of ancestral death and receiving and inheritance}

Having grouped our observations into suitable earnings classes, we next have to estimate the age-dependent probability of ancestral death for members of each of these earnings groups. As inheritances arrive typically only once or twice in a lifetime, receiving an inheritance is an infrequent event in our data. Hence, albeit the fact that we have 163,369 observations, only 2,394 observed households (1.47 percent of our sample) received an inheritance in the sample period. In order to guarantee reliable estimates, we therefore use a coarser definition of age groups, namely 20-34, 35-44, 45-54, 55-64 and 65+ in what follows. For each earnings class $e$ and age group, we calculate the fraction of the observed population in the GSOEP that actually received an inheritance. The results are shown in Table 7 and 8 in Appendix C. We again fit this data using cubic log-polynomials

$$
q_{t}^{e}=\exp \left(\kappa_{0}^{e}+\kappa_{1}^{e} t+\kappa_{2}^{e} t^{2}+\kappa_{3}^{e} t^{3}\right) .
$$

We weigh each moment in the residual sum of squares with the inverse of its standard error in order to control for the varying precision of our estimates. In addition, because of limited sample sizes and in order to reduce the degrees of freedom, we assume that polynomials across households of different earnings classes, but within the same education level (low or high), only vary in the intercept $\kappa_{0}$. All other polynomial coefficients need to be identical for households of the same education level. Finally, we have to control for the fact that a large number of households in our sample is composed of a head and a spouse, and such couples tend to receive an inheritance twice in their lifetime, once from the head's parents and once from the spouse's parents. In order to make the estimated polynomials consistent with our model, we therefore standardize them with a factor of $1+\varsigma^{e}$, where $\varsigma^{e}$ is the fraction of two-person households in each earnings class $e$ in the GSOEP data. Figure 2 shows the resulting polynomials. The share of heirs in a cohort is the highest around ages 50 to 60, which is consistent with a roughly 30 year age difference between parents and children as well as a life expectancy of around 80 years. Higher educated households are more likely to receive an inheritance and tend to get it later in life, mirroring a higher average life expectancy of their (potentially high skilled) parents.

Note that the estimated polynomials represent the share of a cohort that receives an inheritance. In terms of our model, this share is a combination of the probability of the parents deceasing and the likelihood that they pass a positive inheritance to their offspring. Consequently, the polynomials identify

$$
q_{t}^{e}=p_{t}^{e} \sum_{i=1}^{n} \omega_{i}^{e}=p_{t}^{e}\left(1-\omega_{0}^{e}\right) .
$$

Using our structural assumption that parents cannot outlive their children, we immediately get

$$
\sum_{t=1}^{T} q_{t}^{e}=\left(1-\omega_{0}^{e}\right) \sum_{t=1}^{T} p_{t}^{e} \Leftrightarrow \omega_{0}^{e}=1-\sum_{t=1}^{T} q_{t}^{e} .
$$


Figure 2: Estimated age-inheritance relationship for different earnings classes
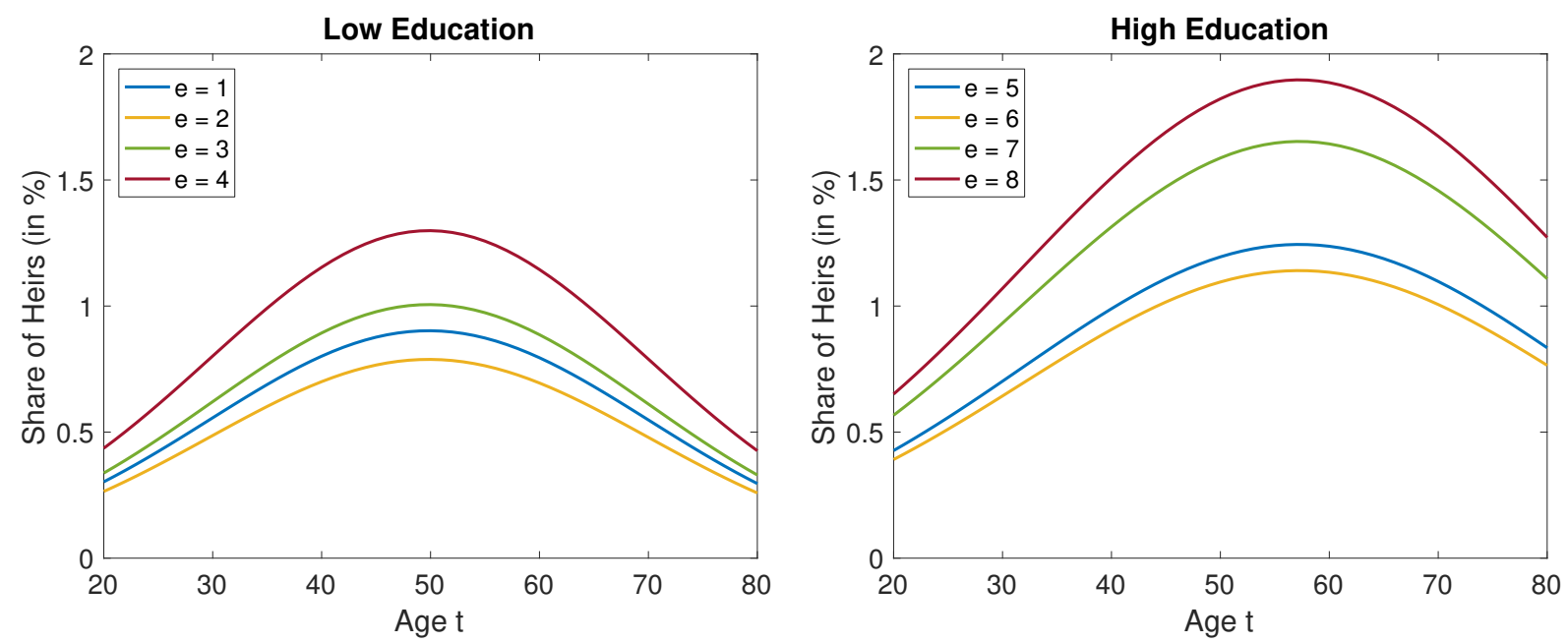

Furthermore, the probabilities of ancestral death are consequently given by

$$
p_{t}^{e}=\frac{q_{t}^{e}}{\sum_{t=1}^{T} q_{t}^{e}} .
$$

\subsubsection{Bequest classes and bequest levels}

In a last step, we have to determine the cross-sectional distribution over (positive) bequest classes $\omega_{i}^{e}, i \in\{1, \ldots, n\}$ as well as the average bequest levels $b_{i t}^{e}$. To this end, we first calculate mean bequests of households who received a positive inheritance for each age group and earnings class in the GSOEP, see Tables 7 and 8 in Appendix C. We again fit this data with cubic log-polynomials using the same methodology as described in the previous section. Figure 3 shows the resulting mean bequest profile by age and earnings level. Interestingly, the mean bequest profiles of the lower skilled are hump-shaped over the life cycle, while those of the high skilled are strictly upward sloping. This could indicate that bequests of parents of lower skilled households tend to be "accidental". If parents follow a regular life-cycle savings pattern and decumulate their wealth at very high ages, bequests fall again. On the other hand, the fact that bequests of parents of higher skilled households increase with the heirs' age indicates that parents consume less than their income speaking in favor of an active bequest motive. This is in line with the view of de Nardi et al. (2010), who model bequests as a luxury good.

In order to determine bequest levels in each bequest class $i$ and for each skill level $e$, we standardize the amount of inheritance of each household in the GSOEP who received a positive bequest by the age group and earnings class specific mean bequest level as reported in Tables 7 and 8 . We then pool together all data for households of one education level, separate the data into quartiles and calculate the mean standardized bequest level for each of these quartiles. The resulting quartile means by education 
Figure 3: Estimated mean bequest profiles for different earnings classes
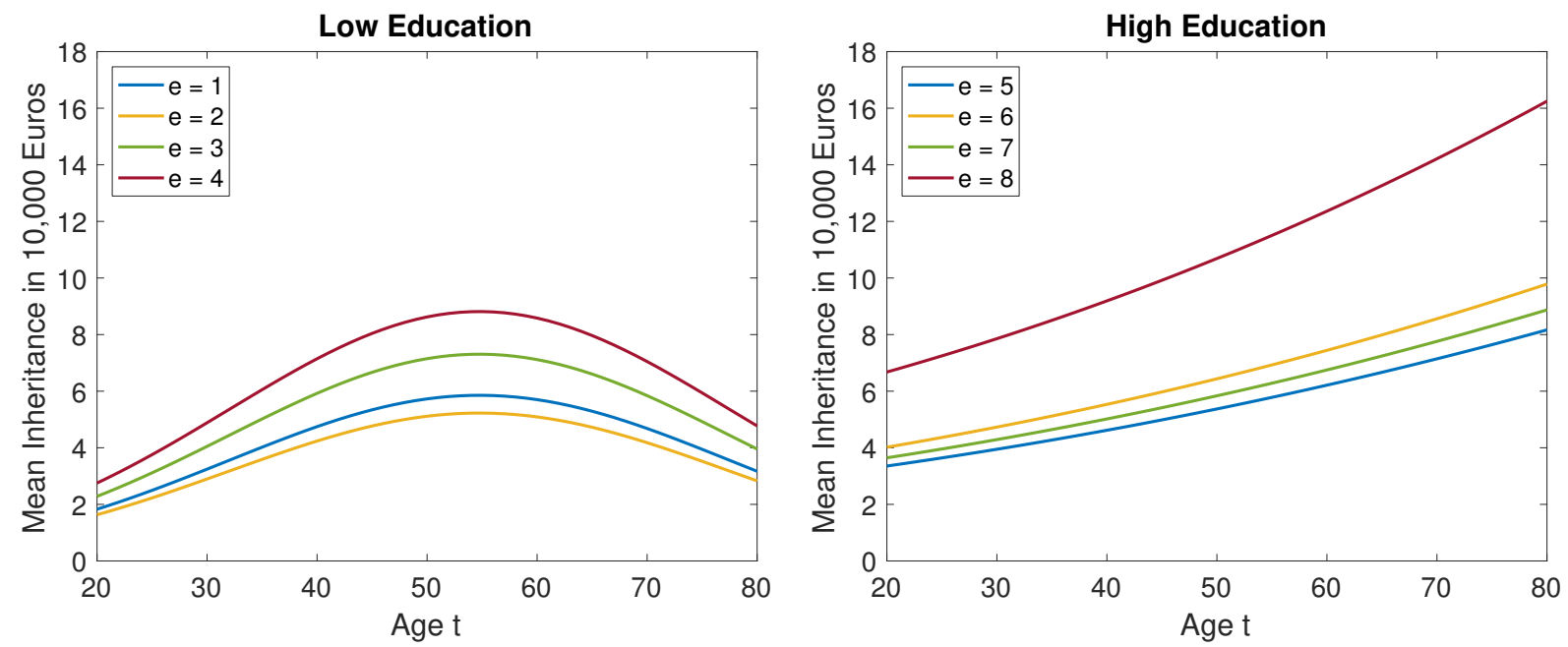

level are shown in Table 1. The table reveals that the distribution of bequests within

Table 1: Standardizes bequest quartile means by education

\begin{tabular}{ccccc}
\hline Education & $\mathrm{Q} 1(i=1)$ & $\mathrm{Q} 2(i=2)$ & $\mathrm{Q} 3(i=3)$ & $\mathrm{Q} 4(i=4)$ \\
\hline Low & 0.070 & 0.232 & 0.611 & 3.095 \\
High & 0.070 & 0.258 & 0.704 & 2.971 \\
\hline
\end{tabular}

the group of heirs is very skewed. While the lowest quartile of heirs receives an average inheritance that amounts to 7 percent of the mean bequest level, the upper quartile's inheritance ranges around three times the mean. The distribution does not differ substantially across households of different education levels. We multiply the mean bequest profiles in Figure 3 with the factors in the above table in order to construct the bequest levels in each bequest class $b_{i t}^{e}$. Since we divided bequests into quartiles, a share $\omega_{i}^{e}=0.25\left(1-\omega_{0}^{e}\right)$ of households in earnings category $e$ is in inheritance class $i$.

\subsection{Parameters, prices and government policy}

Table 2 summarizes our choices for parameters, prices and government policy. Starting their life by the age of $20(t=1)$ we let households live with certainty up to age 80 $(t=61)$, which corresponds to the average life expectancy at birth of the German population. Retirement is mandatory at age 65.

We set the coefficient of risk aversion to $\gamma=1.0$, the labor supply elasticity parameter to $\chi=4.06$, and the time discount factor to $\beta=0.981$. Section 5.3 provides more details on how we jointly pin down these three parameters. Finally, we set the signal 
Table 2: Parameters, prices and government policy

\begin{tabular}{ccl}
\hline Parameter & Value & Note \\
\hline$T$ & 61 & Age of death $=80$ \\
$t_{r}$ & 46 & Retirement age $=65$ \\
\hline$\gamma$ & 1.0 & Coefficient of risk aversion \\
$\chi$ & 4.06 & Frisch elasticity $=0.246$ \\
$\beta$ & 0.981 & Time discount factor \\
$\sigma$ & 0.75 & Signal quality (benchmark) \\
\hline$r$ & $4 \%$ & Interest rate \\
$a_{0}$ & 0 & No initial wealth \\
$a_{\min }$ & $-\infty$ & Only natural borrowing limit \\
\hline $\mathcal{P}$ & 0.40 & Pension $=40 \%$ of average gross income \\
$\tau_{0}$ & 0.321 & Level parameter of labor tax code \\
$\tau_{1}$ & 0.128 & Progressivity of labor tax \\
$\tau_{b}$ & 0.00 & Linear inheritance tax \\
\hline
\end{tabular}

quality to $\sigma=0.75$ in our benchmark scenario. We, however, consider various other scenarios for $\sigma$ in a sensitivity analysis.

Taking a longer run perspective on savings, we take the annual interest rate to be $4 \%$, which is a long-run average return on a diversified portfolio that consists of both stocks and bonds. We furthermore assume that households start their life with zero own wealth. Finally, we assume that the only borrowing limit the household faces is the natural borrowing limit, meaning that they can borrow up to the point where they can still service their debt obligations with certainty. We show in Appendix F.5 that this is a conservative assumption and that the labor supply responses after a change in the inheritance tax are even stronger, when agents are not allowed to borrow at all, that is $a_{\min }=0$.

Finally, we have to specify the tax and pension policy of the government. Starting with the latter, we set the replacement rate of pensions to $40 \%$ of average gross labor earnings over the life cycle, which matches the replacement rate reported by the OECD (2017). We calculate pension payments separately for households of different earnings classes, such that higher earners also receive a higher pension. With regard to labor income taxes, we use data on the mapping from gross into net income provided by Lorenz and Sachs (2016). We fit this data in a least squares sense using a functional form that was first proposed by Benabou (2002) and more recently applied by Heathcote et al. (2017). We therefore write net income as a function of gross income as

$$
y_{\text {net }}=y-\mathcal{T}(y)=\left(1-\tau_{0}\right) y^{1-\tau_{1}},
$$


Figure 4: Net Income and Marginal Tax Rates
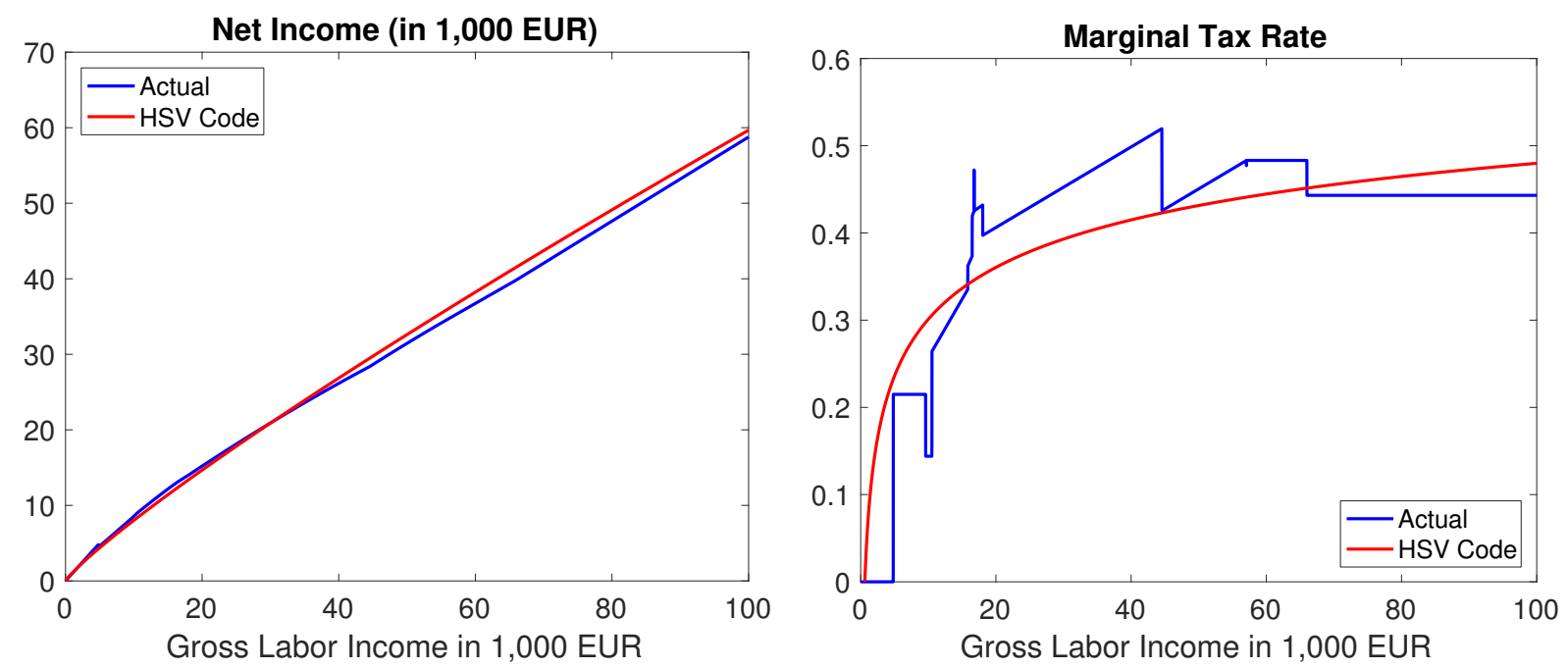

where $\tau_{0}$ roughly captures the average tax rate of the system and $\tau_{1}$ is an index for its progressivity. The left panel of Figure 4 shows the relationship between gross labor income on the $x$-axis and net labor income on the y-axis. The blue line constitutes the original data, the red line is the fitted tax schedule. The parameter set that yields the best match is $\tau_{0}=0.321$ as well as $\tau_{1}=0.128$ with an $R^{2}$ value of 0.998 . The right panel of this figure compares the resulting marginal tax rates. ${ }^{15}$ Last but not least, we assume that in our benchmark simulation bequests are not taxed, which reflects very high exemption levels (400 000 Euro) for inheritances received from parents in Germany.

\subsection{Pinning down wealth effects on labor earnings}

In our model, the derivative of labor earnings with respect to an exogenous and unexpected increase in wealth is given by

$$
\eta_{y, t}=\frac{d y_{t}}{d W_{t}}=-\frac{1-\frac{d a_{t+1}}{d W_{t}}}{\left[1-\tau_{1}+\frac{\chi+\tau_{1}}{\gamma}\right]\left(1-\tau_{0}\right) y_{t}^{-\tau_{1}}+\frac{\chi}{\gamma} \frac{W_{t}-a_{t+1}}{y_{t}}},
$$

see Appendix B for a derivation of this relationship. Note that under a proportional tax code, i.e. with $\tau_{1}=0$, this expression would simply be the generalization of the income effects derived in the three-period model of Section 2. Because of the nonlinear tax schedule, the earnings response to unearned income now also depends on

15 The fit for marginal tax rates is less good than for net income. In Appendix E we argue in detail why it is good enough to answer our policy question. In addition, we neglect welfare benefits and the implied transfer phase-out rates because only $2.3 \%$ of inheritances are received by households who receive some form of welfare benefit. If anything, accounting for it would marginally increase our number of interest because the phase-out rates of welfare benefits would imply higher marginal tax rates at the bottom of the income distribution. 
the degree of tax progressivity, in addition to the ratio $\chi / \gamma$. However, as can be seen in the sensitivity analysis of Appendix F.2, it is still true that in order to generate the same earnings reaction, $\chi / \gamma$ needs to remain roughly constant.

As outlined in the introduction, estimating the impact of inheritances on labor earnings is empirically difficult, as studies can be expected to produce only biased results. In particular, in the data - as in our model - inheritances are not a random and unexpected treatment. Instead, agents rather adjust their economic decisions (such as savings, consumption and labor supply) prior to their arrival, owing to an anticipation effect. A more reliable and convincing source of data comes from a recent study by Cesarini et al. (2017). The authors evaluate the effect of winning the lottery on individual labor earnings using a rich administrative data set of over 250,000 lottery winners in Sweden. Their empirical estimates indicate a marginal propensity to earn out of unearned income of -0.11 before labor taxes and social security contributions of employers. When including employer contributions this number declines to $-0.14 .^{16}$

In order to pin down the wealth effect on labor earnings in our model, we directly use the evidence from Cesarini et al. (2017). More specifically, we randomly pay out lottery gains to our model households, using exactly the lottery size and age distribution provided in their Computational Online Appendix. We then calculate the reduction in labor earnings of all households in the first five years after they won the lottery, measured as a fraction of the amount gained. We target an average annual reduction in labor earnings of $-1.07 \%$ of the lottery win.

As shown in our theoretical analysis, this can be achieved with a whole range of combinations for $\gamma$ and $\chi$, as long as the ratio is approximately constant. In the present case this ratio needs to be around $\gamma / \chi \approx 0.25$. Since we want both, the coefficient of risk aversion and the Frisch elasticity of labor supply to be within the range of empirical estimates, we use $\gamma=1$ and $\chi=4.06$ as our baseline specification. This implies a value for the Frisch elasticity of labor supply of 0.25 , which is in line with empirical estimates. ${ }^{17}$ Furthermore, we calibrate the discount factor $\beta$ such that the steepness of the impulse response function in the model matches its empirical counterpart. Specifically, we target the difference in the labor earnings response in year one and nine after the lottery win. We obtain the best match with a choice of $\beta=0.981$.

16 One concern of lottery studies typically is external validity, meaning that lottery players might be systematically different from the Swedish population at large. Cesarini et al. (2017) address this issue by pulling a random sample from the entire Swedish population, which can be done in Swedish register data. After reweighing this random sample to match the demographic characteristics of the sample of lottery winners, the authors find no significant difference in observable labor market characteristics between lottery players and the general population.

17 A Frisch elasticity of 0.25 is within the range of estimates provided in MaCurdy (1981) and Altonji (1986) for prime age males. Blundell et al. (2016) find slightly higher values for the Frisch labor supply elasticity of males using a sample of married couples and values of around 1 for married females. Fiorito and Zanella (2012) reconcile the consistency between micro- and macro-level estimates. 
A risk aversion of 1 and a Frisch labor supply elasticity of 0.25 both range at the lower end of the spectrum typically found in the life cycle and the macroeconomic literature. However, increasing both risk aversion and the Frisch labor supply elasticity to higher values would significantly increase the wealth effect on labor earnings, which would strongly enforce the labor tax revenue response to an increase in bequest taxes. However, this wealth effect would be inconsistent with empirical evidence. Yet, we provide some sensitivity checks with respect to our parameter choices in Appendix F.2, where we set $\gamma$ at a value smaller than 1, which directly implies a higher Frisch elasticity as well as a value of $\gamma=4$, which implies a high risk aversion.

Figure 5 reports the average impulse response functions of gross and net labor earnings in our model for the first 10 years after a lottery win. Both the gross as well as the (untargeted) net labor earnings response functions show a remarkably good fit with the impulse response data provided in Cesarini et al. (2017). This is of course only

Figure 5: Impulse Response Functions in Data and Model
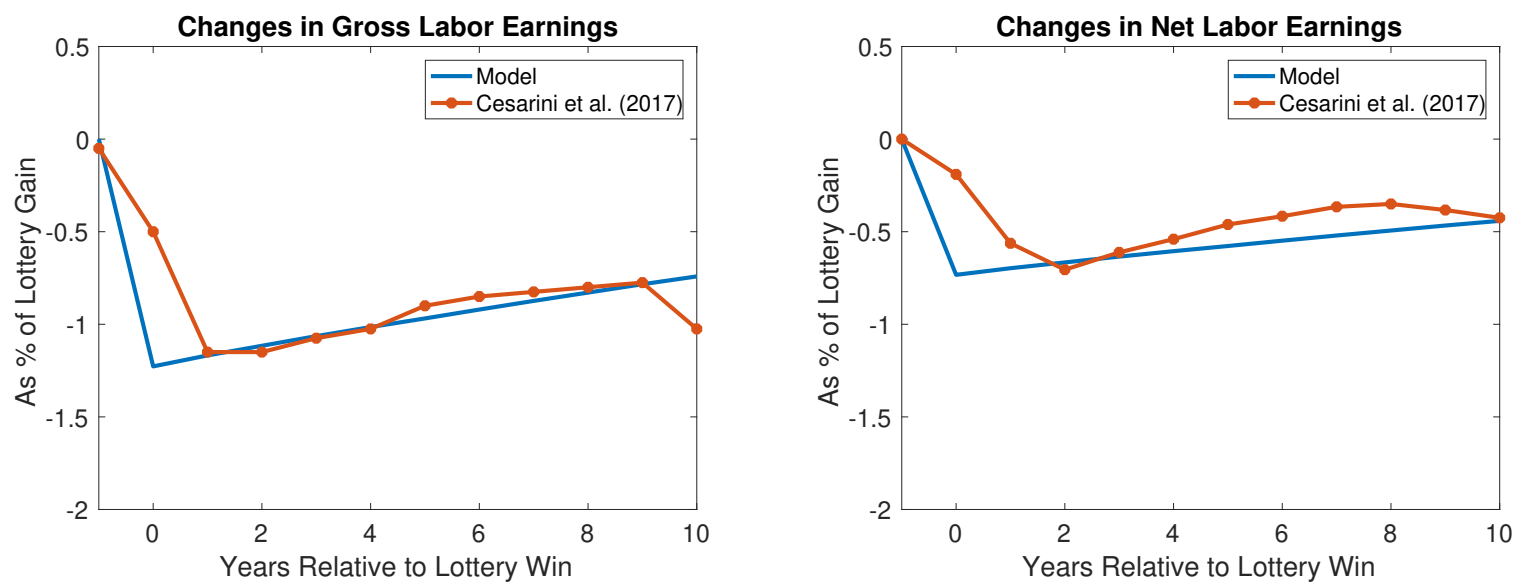

true starting from year one, the year after the lottery gain, since lotteries are paid out at some date throughout year 0, which creates an upward bias in the labor supply response in the data. Note further that, albeit the fact that we paired lottery evidence from Sweden with labor earnings data from Germany, we do get a good fit for both impulse responses in Figure 5, which makes us confident that we do provide valid estimates even with such a mixture of different data sources.

Confidence Bands. As in any empirical study, the estimates in Cesarini et al. (2017) are subject to a certain degree of uncertainty. In order to assess how this uncertainty translates into uncertainty of our results, we re-calibrate $\chi$ twice such that the average yearly gross earnings response in the first five years after the lottery win matches the bounds of the 95\% confidence interval reported in Cesarini et al. (2017). The resulting values are $\chi=6.45$ for the lower bound and $\chi=3.43$ for the upper bound of the confidence interval, implying a Frisch labor supply elasticity in the interval $[0.16,0.29]$. 


\section{Results}

The policy experiment in our numerical simulation model is very similar to the one in the theoretical analysis. Specifically, we assume that the government unexpectedly increases the (proportional) tax rate on bequests by one percentage point. ${ }^{18}$ We start from a case without any inheritance taxes which reflects the large exemption levels for inheritance taxes in Germany. In fact, in our sample, only $2.8 \%$ of inheritances were greater than the status quo exemption level of 400000 Euros for individuals who inherit from their parents. We, for now, focus on the effect a tax increase has on the life cycle behavior of a generation that lives under the new bequest tax rate for all their life. In Section F.1, we illustrate how to measure the effects on short-run generations, who get surprised by a bequest tax change at some date in the middle of their life cycle.

The column Total of Table 3 shows the effect of a one percentage point bequest tax increase on the labor earnings and labor tax payments of one cohort. ${ }^{19}$ In particular, we evaluate the change in the expected present value of labor earnings and labor tax payments of one generation and relate it to the change in this generation's expected present value of bequest tax payments. We find that a one percentage point bequest tax increase leads to an increase in gross earnings of 21.7 cents for each Euro of additional bequest tax payments. This results in a labor tax revenue increase of 8.9 cents. The $95 \%$ confidence interval for the labor earnings response is 14.6 to 24.8 cents, translating into a confidence band for the excess labor income tax revenue of 6.0 to 10.2 cents.

Table 3: Effect of a $1 \%$ increase in bequest taxes

\begin{tabular}{lcccc}
\hline & & \multicolumn{3}{c}{ Decomposition } \\
\cline { 3 - 5 } & Total & Anticipation & Heirs & Non-Heirs \\
\hline Gross Earnings & 21.66 & 10.52 & 11.80 & -0.66 \\
& $(14.59,24.82)$ & $(7.10,12.05)$ & $(7.93,13.55)$ & $(-0.77,-0.43)$ \\
Labor Taxes & 8.87 & 4.24 & 4.90 & -0.27 \\
& $(5.99,10.16)$ & $(2.86,4.86)$ & $(3.30,5.62)$ & $(-0.31,-0.17)$ \\
\hline
\end{tabular}

Effects are measured as fraction of change in bequest tax revenue, $95 \%$ confidence bands in squared brackets.

Our theoretical analysis has shown that the present value of labor earnings and labor tax changes can be decomposed into three components

1. Labor supply of heirs increases owing to the direct negative wealth effect induced

18 In Appendix F.3 we also consider larger tax increases. Our number of interest is by and large unaffected but increases slightly as the tax rate increases.

19 To be precise, in this section we report the results for all cohorts of age 20 or younger (including unborn) at the time of the tax reform. In Appendix F.1 we show the transitional dynamics, i.e. the results for cohorts aged 21 to 64 at the time of the tax reform. 
by a bequest tax increase.

2. The anticipation effect causes households to smooth their labor earnings reaction over the life cycle and leads to higher labor earnings and tax payments already prior to the arrival of an inheritance.

3. As the anticipation effect involves an increase in savings, the resulting negative wealth effect on older cohorts mitigates the earnings reaction of heirs and leads to a decline in labor earnings for non-heirs.

The extent of these effects is shown in the last three columns of Table 3. Both in terms of labor earnings as well as in terms of tax payments, the anticipation effect is almost as large as post-receipt effects. Before uncertainty regarding (potential) inheritances is resolved, agents increase their labor earnings by on average 10.5 cents, leading to additional tax revenues of about 4.2 cents per Euro of bequest taxes. After uncertainty is resolved, those agents who actually inherit pay an additional 4.9 cents in labor income taxes, while non-heirs reduce their tax payments by 0.3 cents.

Our modeling assumption of rational agents with realistic expectations regarding size and timing of bequests implies that anticipation effects are sizable and almost as high as post-receipt effects. In Section 6.4, we discuss a different version of the model in which we postulate that agents are myopic and do not anticipate bequests at all. We show that in such a case, while anticipation effects are by construction zero, postreceipt effects of heirs are higher than the ones we observe here, as myopic individuals do not smooth their labor supply reaction over the entire life cycle.

\subsection{Illustrating the Mechanism}

We now want to elaborate a bit more on the mechanism at work. To this end, Figure 6 shows the change in life cycle savings (upper panels) and earnings (lower panels) in Euro values that results from the one percentage point increase in bequest taxes. As an example, we picked households from a moderate earning class $(e=6)$, who's parents die at the age of 50. On the left hand side, we plot life-cycle graphs for agents who are endowed with a signal of $s=1$ at the beginning of the life cycle, and therefore only expect a very small inheritance. The right hand side shows the same plots for households with a signal of $s=4$, who consequently expect their inheritance to fall into class $i=4$ with probability 0.78 (for a signal quality of $\sigma=0.75$ ). The different lines denote the actual inheritance the household receives $i=0, \ldots, 4$.

The figure shows that upon the increase in bequest taxes, both household types - those with a low and those with a high signal - increase their savings throughout the life cycle, up to the point where they receive an inheritance. Since households with a high signal expect a larger inheritance and therefore experience a greater wealth effect (at least in expectation), their savings reaction is much more pronounced than for the low signal households. Once the inheritance is received, on the other hand, savings typ- 
Figure 6: Change in life-cycle behavior of different households
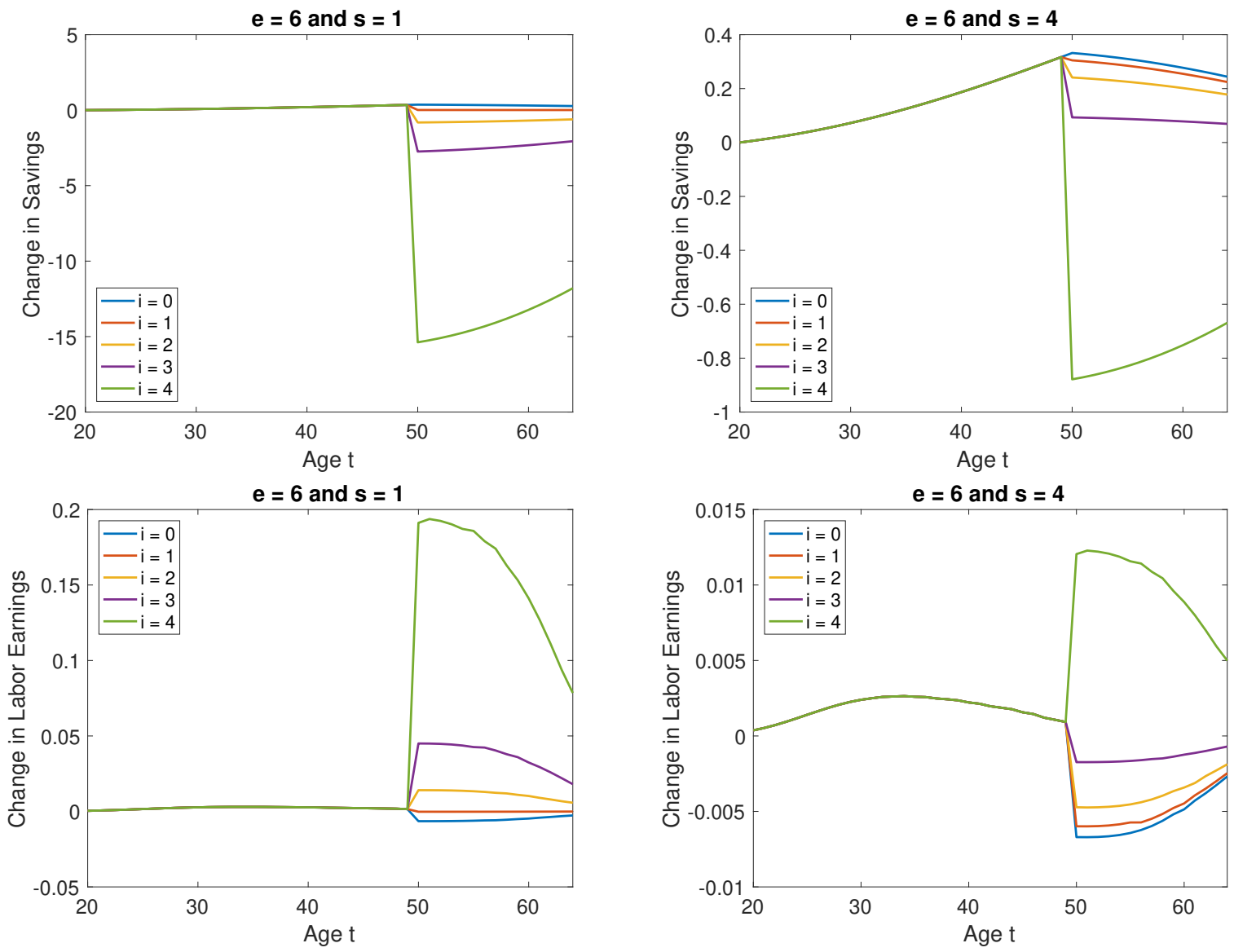

All numbers in percent of the expected bequest conditional on inheriting at age 50 and signal $s$.

ically drop below steady state levels, which is a direct result of the negative wealth effect induced by the bequest tax.

The lower panels of Figure 6 illustrate the importance of the anticipation effect, which first and foremost causes labor earnings to already increase prior to the date at which the household receives an inheritance. As with life-cycle savings, for individuals who expect a large inheritance $(s=4)$, this effect is much more pronounced than for agents with a low signal. Yet, the anticipation effect has a second component: It dampens the labor earning reaction in case the agent receives an inheritance that is greater than her expected inheritance level and causes labor earnings to fall below initial steady state levels in case the expected inheritance is small. Of course, the household endowed with signal $s=4$ has a much higher expectation than the one with $s=1$. Hence, labor earnings of the former fall for all inheritance levels but $i=4$.

\subsection{Heterogeneity of Effects}

Table 4 shows the effects of a one percentage point increase in the bequest tax for households of different earnings classes. In order to control for differences in expected be- 
quests, we normalize the earnings and labor tax effects using the expected present value of bequest tax payments for each earnings level. We find a substantial amount of heterogeneity across labor productivity groups. Specifically, within each education group, higher earnings class households exhibit a greater reaction in labor supply. This

Table 4: Effect of a 1\% increase in bequest taxes by Earnings-Class

\begin{tabular}{|c|c|c|c|c|c|c|c|c|}
\hline \multirow[b]{2}{*}{$e=$} & \multicolumn{4}{|c|}{ Low Education } & \multicolumn{4}{|c|}{ High Education } \\
\hline & 1 & 2 & 3 & 4 & 5 & 6 & 7 & 8 \\
\hline Earnings & 15.01 & 20.57 & 21.53 & 24.07 & 16.30 & 20.22 & 23.40 & 24.38 \\
\hline Taxes & 4.57 & 7.52 & 8.47 & 10.34 & 5.65 & 8.01 & 9.87 & 11.19 \\
\hline
\end{tabular}

Effects are measured as fraction of change in bequest tax revenue by earnings class.

relationship can be understood by realizing that the intratemporal first order condition in our model implies

$$
y_{t}=\left[1-\mathcal{T}^{\prime}\left(y_{t}\right)\right]^{\frac{1}{\chi}} w_{t}^{1+\frac{1}{\chi}}\left(c_{t}\right)^{-\frac{\gamma}{\chi}}
$$

see (25) in Appendix B. From this follows that for any decline in consumption $c_{t}$ (which would be the result of a bequest tax increase), a household with a higher labor productivity will always increase her labor earnings to a greater extent than an agent with low labor productivity.

In economic terms, a higher labor productivity allows a household to counteract changes in exogenous income much easier than an agent with low labor productivity, since a one unit change in labor hours just leads to a much higher change in earnings for the former than for the latter. Or put differently, a one hour reduction in leisure due to lower wealth translates into a larger increase in earnings and therefore consumption the larger the hourly wage is. Note that households with a higher labor productivity also expect to receive larger inheritances, which gives them a higher weight in the calculation of the population-wide average. The heterogeneity in labor tax changes is larger than the heterogeneity in earnings effects across earnings classes. The reason is that, owing to the progressive labor tax schedule, households with higher labor productivity face much higher marginal tax rates.

\subsection{The Role of Signal Quality}

In our benchmark simulation, we chose a signal quality of $\sigma=0.75$. Figure 7 shows the sensitivity of our results with respect to this signal quality. ${ }^{20}$ Recall that for $\sigma=0$, the signal contains no information and all households use the cross-sectional distribution

20 Note that we only vary signal quality and do not recalibrate the labor supply elasticity parameter $\chi$. We however checked for certain combinations that our results also hold under recalibration of $\chi$. 
Figure 7: Varying Signal Quality

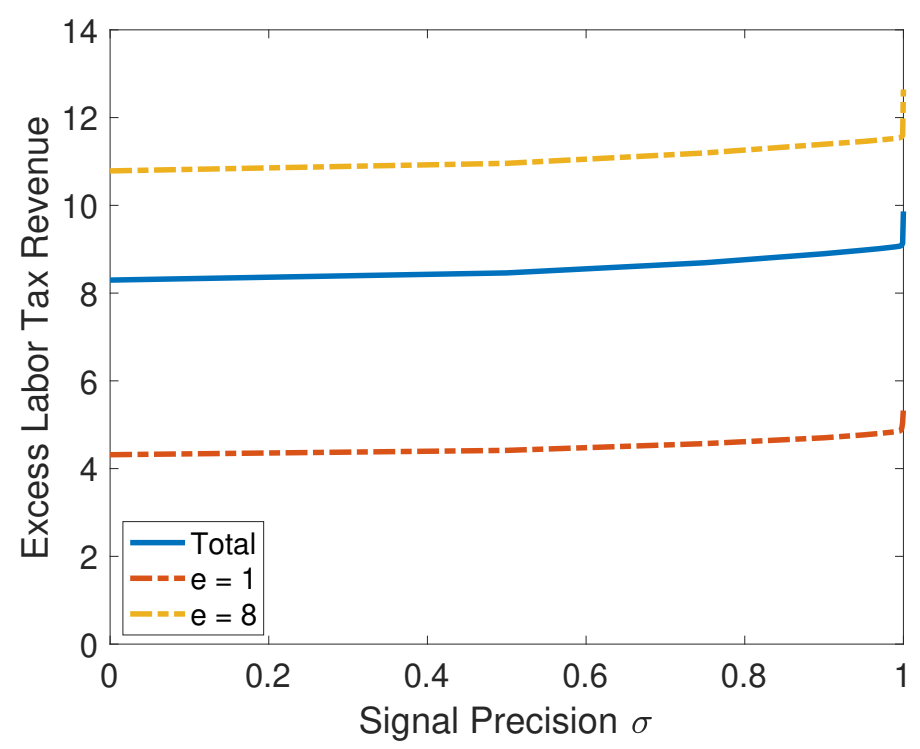

of bequests in their earnings class to forecast the size of their inheritance. For $\sigma=1$, the signal is fully informative and households know exactly in which class their inheritance is going to fall. On the vertical axis of the figure, we again report the excess labor tax effect per unit of additional bequest tax revenue, when we increase the bequest tax rate by one percentage point. We find that, for any $\sigma \ll 1$, labor taxes increase by about the same amount of roughly 8.5 to 9 cents per Euro of additional bequest tax revenue, regardless of the quality of the signal.

Only when the signal quality approaches 1 , this suddenly changes and the excess labor tax revenue increases to about 10 cents. The reason for this can be found in the natural borrowing constraint (Aiyagari, 1994) of a household. Whenever the signal is less than fully informative, a household can make some forecast about her future inheritance. Yet, there still is the possibility that the agent ends up inheriting nothing. Households would obviously like to distribute the benefits of the expected bequest (that are typically received around the age of 50 to 60) evenly over the life cycle. Those with a higher expected inheritance might therefore even run into debt against future bequest transfers. The amount of debt they can hold is limited by the natural borrowing constraint. In case there is even a slight chance of inheriting nothing, the agent has to make sure that she can still service her debt in case she gets no bequest from her parents. Hence, her natural borrowing limit is relatively tight, even if on average she expects a large bequest. This suddenly changes with a fully informative signal. In this case, the only remaining uncertainty is the uncertainty about timing. But eventually, every household with a positive signal will receive a positive bequest. Hence, life-cycle smoothing works much better in this scenario, as the natural borrowing constraint is relaxed. As a result, agents who have a high expectation about bequests will also react 
much stronger to changes in bequest taxes. In Figure 7 this fact can be seen when comparing the change in excess labor taxes for households from a low earnings class, who on average have low expectations about inheritances, with those from a high earnings class.

\subsection{Myopic vs. Forward Looking Agents}

So far, we assumed that agents are fully rational, in the sense that they anticipate the (potential) receipt of bequests. Consequently, they adjust their labor supply and savings decisions to changes in inheritance taxes already from the beginning of their economic life. While this assumption is a natural benchmark, one might argue that in reality, agents are not perfectly forward looking. In fact, the behavioral literature suggests that agents often act myopically and don't pay too much attention to (potential) future events, see e.g. Gabaix (2019). To elaborate on this issue, we consider a polar case in which agents do not anticipate the receipt of inheritances at all, but are completely surprised by the arrival of a bequest. In this version of the model, an inheritance triggers responses equivalent to those after a lottery win and anticipation effects are absent by construction.

We again perform our policy experiment and increase the inheritance tax from zero to $1 \%$. The results are shown in Table 5. In total, labor earnings increase by about 14.3

Table 5: Effect of a $1 \%$ increase in bequest taxes, myopic agents

\begin{tabular}{lcccc}
\hline & & \multicolumn{3}{c}{ Decomposition } \\
\cline { 3 - 5 } & Total & Anticipation & Heirs & Non-Heirs \\
\hline Gross Earnings & 14.32 & 0.00 & 14.32 & 0.00 \\
Labor Taxes & 5.97 & 0.00 & 5.97 & 0.00 \\
\hline
\end{tabular}

Effects are measured as fraction of change in bequest tax revenue.

cents per Euro of mechanically raised bequest tax revenue. Labor income taxes rise by almost 6 cents. Both of these numbers are by about one third lower than in the benchmark case of forward looking agents, see Table 3. Of course, the anticipation effect is zero by assumption and, after uncertainty about bequests is resolved, only heirs respond to the change in taxes. Yet, the increase in heirs' labor earnings (and therefore income taxes paid) is greater than the post-receipt response of anticipating heirs in the benchmark case. The reason is that fully rational heirs distribute the burden of a bequest tax increase over their whole life-cycle using adjustments in savings. Myopic heirs, however, fail to internalize this burden prior to the inheritance receipt and consequently have to react more strongly afterwards. However, as most inheritances arrive rather late in life, their scope of action is rather limited. As a result, their overall labor supply response is much lower than the total response of a rational individual. 


\subsection{Further Thoughts and Extensions}

Elastic Bequests. By focusing on behavior of heirs, we also implicitly assumed that bequests are inelastic with respect to bequest taxes. How does this affect our results? With elastic bequests, an increase in the bequest tax would also lead to a decrease in bequests. Then an increase in the bequest tax decreases net bequests for two reasons: first it does so mechanically and this is the channel we take into account. Second, even gross bequests will be reduced if the bequest elasticity is positive. Hence, net bequests decrease even more. This would reinforce the wealth effect on labor supply of the heirs. In an earlier version of this paper (Kindermann et al., 2018), we state this result more formally in Corollary 2 . The wealth effect simply gets multiplied by one plus the elasticity of bequests. In general equilibrium, however, a change in bequests might also have effects on productivity and factor prices, if bequests were, for example, transmitted between generations in the form of productive capital.

The Origin of Bequests. It is important to note that while the agents in our model are (potential) heirs, they do not leave inheritances themselves. In this sense our model is in partial equilibrium as the distribution of bequests the agents receive is exogenous. Accounting for the endogeneity of bequests would require a full dynastic OLG model, which is beyond the scope of this paper and should be left to future research.

Revenue-Neutral Reforms. Such a dynastic model would also allow to study revenueneutral reforms, where tax revenue raised by the government will eventually end up back in the hands of households. Reimbursing tax revenue back to households might then again affect individual decisions. Our partial equilibrium model does not allow to study such reforms because we do not model bequeathers. For bequeathers, there would be income- and substitution effects on the labor supply and bequest decisions (Hines, 2013). If we were to simulate all these effects, following the spirit of an optimal tax analysis, we would use the bequest tax revenue raised from bequeathers to undo their very income effect, such that the labor supply and bequest reaction of this group is governed solely by substitution effects, i.e. the compensated own- and cross-price elasticities. ${ }^{21}$ In addition, we would reimburse the excess labor tax revenue collected from heirs in a lump-sum fashion back to the group of heirs. While our model doesn't allow us to study the consequences of the former exercise, we can still do the latter. We find that, in such a scenario, heirs' labor earnings increase by only 19.53 Cent (instead of 21.66 Cent in our baseline scenario) per Euro of bequest tax revenue raised, while labor income taxes increase by only 8.05 Cent (instead of 8.87 Cent).

Capital Income Taxes. While both our theoretical and our quantitative analysis focuses on labor income tax revenue, it is worth noting that in principle also capital income tax revenue is affected through the change in savings behavior after the tax reform. How-

21 In fact, since there is heterogeneity in bequests, income effect parameters could also play a role if they differed across bequeathers. This is because lump-sum redistribution leads those who give bequests below average to get richer and those how give above average to get poorer. 
ever, in Germany most of capital income is untaxed because (i) Germans hold around $83 \%$ of their wealth in assets that are not subject to capital income taxes (e.g. houses), and (ii) there exists a relatively large exemption level for income from assets subject to the tax, implying that only around $12 \%$ of households pay some capital income tax. ${ }^{22}$ As a consequence, the implied change in capital tax revenue is of second-order importance as compared to the labor income tax revenue. For details, see Appendix F.4.

\section{Conclusion}

In this paper we theoretically and quantitatively characterize the effects of inheritance tax increases on public finances. We focus on one particular channel through which tax revenues are affected: labor supply increases of (potential) heirs as a result of negative wealth effects and the corresponding increase in labor income tax revenues. In a theoretical framework we show how this channel can be decomposed into: a direct wealth effect on heirs, and an anticipation effect on all individuals even prior to the receipt of an inheritance.

We then quantify the labor tax revenue effect of bequest taxes using a state of the art life-cycle model that is calibrated to match clean quasi-experimental evidence on wealth effects of lottery winners. In our preferred calibration, for each Euro of inheritance taxes that the government collects, it gets on average an additional 9 cents from increased labor income tax payments of heirs and of agents who do not inherit, but expect to with a certain probability. This is a sizable effect and should therefore be taken into account in dynamic scoring exercises.

One margin that we do not account for and which could make the effects even stronger are education decisions. It is likely that individuals do not only make their labor supply choices conditional on their expectations about inheritances, but also adjust the acquisition of human capital accordingly. In that sense, an increase in inheritance taxes could also imply a positive effect on the education of heirs, which would imply another positive effect on labor income tax revenue. In addition, we only consider intensive margin labor supply adjustments, while extensive labor supply choices might also play a role. This could be especially true for households who receive an inheritance very late in their working life and adjust their retirement behavior accordingly.

22 We documented these numbers from the Bundesbank Panel on Household Finances. 


\section{References}

Aiyagari, S. R. (1994). Uninsured Idiosyncratic Risk and Aggregate Saving. The Quarterly Journal of Economics, 109(3):659-684.

Altonji, J. (1986). Intertemporal Substitution in Labor Supply: Evidence from Micro Data. Journal of Political Economy, 94(3):S176-S215.

Benabou, R. (2002). Tax and Education Policy in a Heterogeneous Agent Economy: What Levels of Redistribution Maximize Growth and Efficiency? Econometrica, 70(2):481-517.

Bick, A., Fuchs-Schündeln, N., and Lagakos, D. (2018). How do Hours Worked Vary with Income? Cross-Country Evidence and Implications. American Economic Review, 108(1):170-99.

Blundell, R., Pistaferri, L., and Saporta-Eksten, I. (2016). Consumption Inequality and Family Labor Supply. American Economic Review, 106(2):387-435.

Bø, E. E., Halvorsen, E., and Thoresen, T. O. (2018). Heterogeneity of the Carnegie Effect. Journal of Human Resources, pages 0915-7366R1.

Brown, J. R., Coile, C. C., and Weisbenner, S. J. (2010). The Effect of Inheritance Receipt on Retirement. Review of Economics and Statistics, 92:425-434.

Carnegie, A. (1891). The Adavantages of Poverty. The Nineteenth Century and After: A Monthly Review, 29(169):367-385.

Cesarini, D., Lindqvist, E., Notowidigdo, M. J., and Ostling, R. (2017). The Effect of Wealth on Individual and Household Labor Supply: Evidence from Swedish Lotteries. American Economic Review, 107(12):3917-3946.

de Nardi, M., French, E., and Jones, J. (2010). Why Do the Elderly Save? The Role of Medical Expenses. Journal of Political Economy, 118(1):39-75.

Doorley, K. and Pestel, N. (2016). Labor Supply After Inheritances and the Role of Expectations. IZA Discussion Paper No. 9822.

Elinder, M., Erixson, O., and Ohlsson, H. (2012). The Impact of Inheritances on Heirs' Labor and Capital Income. The BE Journal of Economic Analysis E Policy, 12(1).

Fiorito, R. and Zanella, G. (2012). The Anatomy of the Aggregate Labor Supply Elasticity. Review of Economic Dynamics, 15(2):171-187.

Gabaix, X. (2019). Behavioral Inattention. In Bernheim, D., DellaVigna, S., and Laibson, D., editors, Handbook of Behavioral Economics, volume 1. Elsevier. 
Gelber, A., Moore, T. J., and Strand, A. (2017). The Effect of Disability Insurance Payments on Beneficiaries' Earnings. American Economic Journal: Economic Policy, 9(3):229-61.

Golosov, M., Kocherlakota, N., and Tsyvinski, A. (2003). Optimal Indirect and Capital Taxation. Review of Economic Studies, 70(3):569-587.

Heathcote, J., Storesletten, K., and Violante, G. (2017). Optimal Tax Progressivity: An Analytical Framework. Quarterly Journal of Economics, 132(4):1693-1754.

Hines, J. (2013). Income and Substitution Effects of Estate Taxation. American Economic Review: Papers and Proceedings, 103(3):484-488.

Holtz-Eakin, D., Joulfaian, D., and Rosen, H. S. (1993). The Carnegie Conjecture: Some Empirical Evidence. The Quarterly Journal of Economics, 108(2):413-435.

Imbens, G. W., Rubin, D. B., and Sacerdote, B. I. (2001). Estimating the Effect of Unearned Income on Labor Earnings, Savings, and Consumption: Evidence from a Survey of Lottery Players. American Economic Review, pages 778-794.

Jacobs, B. and Schindler, D. (2012). On the Desirability of Taxing Capital Income in Optimal Social Insurance. Journal of Public Economics, 96(9-10):853-868.

Kindermann, F., Mayr, L., and Sachs, D. (2018). Inheritance Taxation and Wealth Effects on the Labor Supply of Heirs. NBER Working Paper No. 25081.

Kocherlakota, N. (2010). The New Dynamic Public Finance. Princeton University Press.

Koeniger, W. and Prat, J. (2018). Human Capital and Optimal Redistribution. Review of Economic Dynamics, 27:1-26.

Kopczuk, W. (2013a). Incentive Effects of Inheritances and Optimal Estate Taxation. American Economic Review: Papers and Proceedings, 103(3):472-77.

Kopczuk, W. (2013b). Taxation of Intergenerational Transfers and Wealth. In Auerbach, A. J., Chetty, R., Feldstein, M., and Saez, E., editors, Handbook of Public Economics, volume 5, pages 329-390. Elsevier.

Lorenz, N. and Sachs, D. (2016). Identifying Laffer Bounds: A Sufficient Statistics Approach with an Application to Germany. The Scandinacian Journal of Economics, 118(4):646-665.

MaCurdy, T. (1981). An Empirical Model of Labor Supply in a Life-Cycle Setting. Journal of Political Economy, 89(6):1059-1085.

OECD (2017). Pensions at a Glance 2017: OECD and G20 Indicators. OECD Publishing, Paris. 
Picchio, M., Suetens, S., and Van Ours, J. C. (2018). Labor Supply Effects of Winning a Lottery. The Economic Journal, 128(611):1700-1729.

Piketty, T. (2011). On the Long-Run Evolution of Inheritance: France 1820-2050. The Quarterly Journal of Economics, 126(3):1071-1131.

Saez, E. (2001). Using Elasticities to Derive Optimal Income Tax Rates. Review of Economic Studies, 68(1):205-229.

Saez, E., Slemrod, J., and Giertz, S. H. (2012). The Elasticity of Taxable Income with Respect to Marginal Tax Rates: A Critical Review. Journal of Economic Literature, 50(1):3-50.

Wagner, G., Frick, J., and Schupp, J. (2007). The German Socio-Economic Panel Study (SOEP) - Scope, Evolution and Enhancements. Journal of Applied Social Science Studies, 127(1):139-169. 


\section{Appendix}

\section{A Results from the three-period model framework}

\section{A.1 A Static Model}

Households have to solve the optimization problem

$$
\max _{c, l} \frac{c^{1-\gamma}}{1-\gamma}-\frac{l^{1+\chi}}{1+\chi} \quad \text { s.t. } \quad c \leq(1-\tau) w l+R .
$$

The first order condition of this problem reads

$$
c^{-\gamma}=\frac{l \chi}{(1-\tau) w} .
$$

Acknowledging that the budget constraint holds with equality, we can write the equation defining labor earnings as

$$
(1-\tau) w^{1+\chi}[(1-\tau) y+R]^{-\gamma}-y^{\chi}=0 .
$$

Total differentiation yields

$$
\begin{aligned}
{\left[-\gamma(1-\tau) w^{1+\chi}[(1-\tau) y+R]^{-\gamma-1}(1-\tau)-\chi y^{\chi-1}\right] d y } & \\
& -\gamma(1-\tau) w^{1+\chi}[(1-\tau) y+R]^{-\gamma-1} d R=0
\end{aligned}
$$

from which we obtain

$$
\begin{gathered}
{\left[-\gamma \frac{(1-\tau) y^{\chi}}{(1-\tau) y+R}-\chi \frac{y^{\chi}}{y}\right] d y-\gamma \frac{y^{\chi}}{(1-\tau) y+R} d R=0} \\
\Rightarrow \quad \eta=\frac{d y}{d R}=-\frac{1}{\gamma(1-\tau)+\chi \frac{(1-\tau) y+R}{y}}=-\frac{1}{\left(1+\frac{\chi}{\gamma}\right)(1-\tau)+\frac{\chi}{\gamma} \frac{R}{y}} .
\end{gathered}
$$

\section{A.2 Impulse Responses and Intertemporal Labor Supply}

\section{Proof of Proposition 1}

Households maximize

$$
\max _{c_{1}, l_{1}, c_{2}, l_{2}} \frac{c_{1}^{1-\gamma}}{1-\gamma}-\frac{l_{1}^{1+\chi}}{1+\chi}+\beta\left[\frac{c_{2}^{1-\gamma}}{1-\gamma}-\frac{l_{2}^{1+\chi}}{1+\chi}\right]
$$


subject to the budget constraint

$$
c_{1}+\frac{c_{2}}{1+r} \leq(1-\tau)\left[w_{1} l_{1}+\frac{w_{2} l_{2}}{1+r}\right]+\left(1-\tau_{b}\right) b+T_{1}+\frac{T_{2}}{1+r} .
$$

The first order conditions of the problem read

$$
\begin{aligned}
& c_{2}=[\beta(1+r)]^{\frac{1}{\gamma}} c_{1} \\
& l_{2}=\left[\frac{w_{2}}{w_{1}}\right]^{\frac{1}{\chi}}[\beta(1+r)]^{-\frac{1}{\chi}} l_{1} \\
& c_{1}=\left[(1-\tau) w_{1}\right]^{\frac{1}{\gamma}}\left(l_{1}\right)^{-\frac{\chi}{\gamma}} .
\end{aligned}
$$

Plugging the intertemporal conditions into the budget constraint yields

$$
c_{1} \underbrace{\left[1+\beta^{\frac{1}{\gamma}}(1+r)^{\frac{1}{\gamma}-1}\right]}_{=: \Psi_{c}}=(1-\tau) w_{1} l_{1} \underbrace{\left[1+\left[\frac{w_{2}}{w_{1}}\right]^{1+\frac{1}{\chi}} \beta^{-\frac{1}{\chi}}(1+r)^{-\frac{1}{\chi}-1}\right]}_{=: \Psi_{l}}+R .
$$

The intra-period first order condition then leads us to

$$
\Psi_{c}\left[(1-\tau) w_{1}\right]^{\frac{1}{\gamma}} l_{1}^{-\frac{\chi}{\gamma}}=\Psi_{l}(1-\tau) w_{1} l_{1}+R,
$$

which we can write in terms of labor earnings as

$$
\Psi_{c}(1-\tau)^{\frac{1}{\gamma}} w_{1}^{\frac{1+\chi}{\gamma}} y_{1}^{-\frac{\chi}{\gamma}}=\Psi_{l}(1-\tau) y_{1}+R
$$

Total differentiation yields

$$
\left[\Psi_{l}(1-\tau)+\frac{\chi}{\gamma} \Psi_{c}(1-\tau)^{\frac{1}{\gamma}} w_{1}^{\frac{1+\chi}{\gamma}} y_{1}^{-\frac{\chi}{\gamma}-1}\right] d y_{1}+d R=0
$$

from which follows

$$
\begin{aligned}
\frac{d y_{1}}{d R} & =-\frac{1}{\Psi_{l}(1-\tau)+\frac{\chi}{\gamma} \Psi_{c}(1-\tau)^{\frac{1}{\gamma}} w_{1}^{\frac{1+\chi}{\gamma}} y_{1}^{-\frac{\chi}{\gamma}-1}} \\
& =-\frac{y_{1}}{\Psi_{l}(1-\tau) y_{1}+\frac{\chi}{\gamma}\left[\Psi_{l}(1-\tau) y_{1}+R\right]} \\
& =-\frac{1}{\Psi_{l}\left(1+\frac{\chi}{\gamma}\right)(1-\tau)+\frac{R}{y_{1}}}
\end{aligned}
$$

We can write the intertemporal first-order condition regarding labor supply in terms of labor earnings as

$$
y_{2}=\left[\frac{w_{2}}{w_{1}}\right]^{1+\frac{1}{\chi}}[\beta(1+r)]^{-\frac{1}{\chi}} y_{1}
$$


from which we directly obtain that

$$
d y_{2}=\left[\frac{w_{2}}{w_{1}}\right]^{1+\frac{1}{\chi}}[\beta(1+r)]^{-\frac{1}{\chi}} d y_{1}
$$

Consequently, the change in the present value of labor earnings is

$$
\begin{aligned}
\eta=\frac{d y_{1}+\frac{d y_{2}}{1+r}}{d R} & =\left[1+\left[\frac{w_{2}}{w_{1}}\right]^{1+\frac{1}{\chi}} \beta^{-\frac{1}{\chi}}(1+r)^{-\frac{1}{\chi}-1}\right] \frac{d y_{1}}{d R}=\Psi_{l} \frac{d y_{1}}{d R} \\
& =-\frac{1}{\left(1+\frac{\chi}{\gamma}\right)(1-\tau)+\frac{R}{\Psi_{l} y_{1}}} \\
& =-\frac{1}{\left(1+\frac{\chi}{\gamma}\right)(1-\tau)+\frac{R}{y}} .
\end{aligned}
$$

\section{Proof of Proposition 2}

Proposition 2 is a direct consequence of (11).

\section{A.3 Intertemporal Labor Supply in a More General Setup}

Assume we want to solve a generalized version of the model setup in Section 2.2. Households maximize utility

$$
\max _{c_{1}, c_{2}, l_{1}, l_{2}} u\left(c_{1}, l_{1}\right)+\beta u\left(c_{2}, l_{2}\right)
$$

subject to the intertemporal budget constraint

$$
c_{1}+\frac{c_{2}}{1+r}=(1-\tau) w_{1} l_{1}+\frac{(1-\tau) w_{2} l_{2}}{1+r}+R,
$$

where notation is identical to Section 2.2.

The first-order conditions of this problem read

$$
\begin{aligned}
u_{c}^{1} & =\beta(1+r) u_{c}^{2} \\
\frac{u_{l}^{1}}{(1-\tau) w_{1}} & =\beta(1+r) \frac{u_{l}^{2}}{(1-\tau) w_{2}} \\
u_{c}^{i} & =-\frac{u_{l}^{i}}{(1-\tau) w_{i}},
\end{aligned}
$$

where we use the notation

$$
u_{l}^{i}=\frac{\partial u\left(c_{i}, l_{i}\right)}{\partial l_{i}} \quad \text { and } \quad u_{c}^{i}=\frac{\partial u\left(c_{i}, l_{i}\right)}{\partial c_{i}} .
$$


Hence, the household equalizes marginal (dis-)utilities of consumption and labor supply, weighted by their respective prices. Total differentiation of the first-order conditions yields

$$
\begin{aligned}
& u_{c c}^{1} d c_{1}+u_{c l}^{1} d l_{1}=\beta(1+r)\left[u_{c c}^{2} d c_{2}+u_{c l}^{2} d l_{2}\right] \\
& \frac{u_{l l}^{1} d l_{1}+u_{c l}^{1} d c_{1}}{(1-\tau) w_{1}}=\beta(1+r) \frac{u_{l l}^{2} d l_{2}+u_{c l}^{2} d c_{2}}{(1-\tau) w_{2}} \\
& u_{c c}^{i} d c_{i}+u_{c l}^{i} d l_{i}=-\frac{u_{l l}^{i} d l_{i}+u_{c l}^{i} d c_{i}}{(1-\tau) w_{i}}
\end{aligned}
$$

with notation

$$
u_{l l}^{i}=\frac{\partial^{2} u\left(c_{i}, l_{i}\right)}{\partial\left(l_{i}\right)^{2}} \quad, \quad u_{c c}^{i}=\frac{\partial^{2} u\left(c_{i}, l_{i}\right)}{\partial\left(c_{i}\right)^{2}} \quad \text { and } \quad u_{c l}^{i}=\frac{\partial^{2} u\left(c_{i}, l_{i}\right)}{\partial c_{i} \partial l_{i}}
$$

where $i=1,2$ indicates the respective period.

Before we continue with solving for an expression for the changes in labor earnings, we want to rewrite the above equations (12)-(14) in terms of relative changes and elasticities. We therefore divide (12) by $u_{c}^{1}$ and obtain

$$
\frac{u_{c c}^{1} c_{1}}{u_{c}^{1}} \frac{d c_{1}}{c_{1}}+\frac{u_{c l}^{1} l_{1}}{u_{c}^{1}} \frac{d y_{1}}{y_{1}}=\frac{u_{c c}^{2} c_{2}}{u_{c}^{2}} \frac{d c_{2}}{c_{2}}+\frac{u_{c l}^{2} l_{2}}{u_{c}^{2}} \frac{d y_{2}}{y_{2}} .
$$

Note that we used $\frac{d l_{1}}{l_{1}}=\frac{d y_{1}}{y_{1}}$ as well as the first order condition $\frac{\beta(1+r)}{u_{c}^{1}}=\frac{1}{u_{c}^{2}}$. In exactly the same way, (13) can be rewritten as

$$
\frac{u_{l l}^{1} l_{1}}{u_{l}^{1}} \frac{d y_{1}}{y_{1}}+\frac{u_{c l}^{1} c_{1}}{u_{l}^{1}} \frac{d c_{1}}{c_{1}}=\frac{u_{l l}^{2} l_{2}}{u_{l}^{2}} \frac{d y_{2}}{y_{2}}+\frac{u_{c l}^{2} c_{2}}{u_{l}^{2}} \frac{d c_{2}}{c_{2}} .
$$

The differential of the intra-temporal first order condition then yields

$$
\left[\frac{u_{c c}^{i} c_{i}}{u_{c}^{i}}-\frac{u_{c l}^{i} c_{i}}{u_{l}^{i}}\right] \frac{d c_{i}}{c_{i}}=\left[\frac{u_{l l}^{i} l_{i}}{u_{l}^{i}}-\frac{u_{c l}^{i} l_{i}}{u_{c}^{i}}\right] \frac{d y_{i}}{y_{i}} .
$$

From (17), we directly obtain a relationship between the relative change in period $i$ consumption and labor income:

$$
\frac{d c_{i}}{c_{i}}=\frac{\frac{u_{l l}^{i} l_{i}}{u_{l}^{i}}-\frac{u_{c l}^{i} l_{i}}{u_{c}^{i}}}{\frac{u_{c c}^{i} c_{i}}{u_{c}^{i}}-\frac{u_{c l}^{i} c_{i}}{u_{l}^{i}}} \frac{d y_{i}}{y_{i}} .
$$

Plugging (18) into (16) then yields

$$
\begin{aligned}
& \frac{u_{l l}^{1} l_{1}}{u_{l}^{1}} \frac{d y_{1}}{y_{1}}+\frac{u_{c l}^{1} c_{1}}{u_{l}^{1}} \frac{\frac{u_{l l}^{1} l_{1}}{u_{l}^{1}}-\frac{u_{c l}^{1} l_{1}}{u_{c}^{1}}}{\frac{u_{c c}^{1} c_{1}}{u_{c}^{1}}-\frac{u_{c l}^{1} c_{1}}{u_{l}^{1}}} \frac{d y_{1}}{y_{1}}=\frac{u_{l l}^{2} l_{2}}{u_{l}^{2}} \frac{d y_{2}}{y_{2}}+\frac{u_{c l}^{2} c_{2}}{u_{l}^{2}} \frac{\frac{u_{l l}^{2} l_{2}}{u_{l}^{2}}-\frac{u_{c l}^{2} l_{2}}{u_{c}^{2}}}{\frac{u_{c c}^{2} c_{2}}{u_{c}^{2}}-\frac{u_{c l}^{2} c_{2}}{u_{l}^{2}}} \frac{d y_{2}}{y_{2}} \\
\Leftrightarrow & \frac{\frac{u_{c c}^{1} c_{1}}{u_{c}^{1}}\left[\frac{u_{l l}^{1} l_{1}}{u_{l}^{1}}-\frac{\left(u_{c l}^{1}\right)^{2} l_{1}}{u_{c c}^{1} u_{l}^{1}}\right]}{\frac{u_{c c}^{1} c_{1}}{u_{c}^{1}}-\frac{u_{c l}^{1} c_{1}}{u_{l}^{1}}} \frac{d y_{1}}{y_{1}}=\frac{\frac{u_{c c}^{2} c_{2}}{u_{c}^{2}}\left[\frac{u_{l l}^{2} l_{2}}{u_{l}^{2}}-\frac{\left(u_{c l}^{2}\right)^{2} l_{2}}{u_{c c}^{2} u_{l}^{2}}\right]}{\frac{u_{c c}^{2} c_{2}}{u_{c}^{2}}-\frac{u_{c l}^{2} c_{2}}{u_{2}^{1}}} \frac{d y_{2}}{y_{2}}
\end{aligned}
$$




\section{Some intuition}

Before we move on with narrowing down the change in the present value of labor earnings to a change in unearned income, we want to develop some intuition for the two central relationships (18) and (19). Starting with equation (18), we can see that the relative change in consumption and labor earnings are linked by the two elasticities

$$
\sigma_{l}^{i}=\left[\frac{u_{l l}^{i}}{u_{l}^{i}}-\frac{u_{c l}^{i}}{u_{c}^{i}}\right] l_{i} \text { and } \sigma_{c}^{i}=\left[\frac{u_{c c}^{i}}{u_{c}^{i}}-\frac{u_{c l}^{i}}{u_{l}^{i}}\right] c_{i} \quad \text { so that } \frac{d c_{i}}{c_{i}}=\frac{\sigma_{l}^{i}}{\sigma_{c}^{i}} \frac{d y_{i}}{y_{i}}
$$

Those elasticities link to the intratemporal elasticity of substitution between consumption and labor supply

$$
E_{l_{i} c_{i}}=\frac{d \log \left(\frac{l_{i}}{c_{i}}\right)}{d \log \left(\frac{u_{l}^{i}}{u_{c}^{i}}\right)}=\frac{\frac{d l_{i}}{l_{i}}-\frac{d c_{i}}{c_{i}}}{\sigma_{l}^{i} \frac{d l_{i}}{l_{i}}-\sigma_{c}^{i} \frac{d c_{i}}{c_{i}}} .
$$

Specifically, if the intratemporal elasticity of substitution is constant, we have $E_{l_{i} c_{i}}=$ $\frac{1}{\sigma_{l}^{i}}=\frac{1}{\sigma_{c}^{i}}$. More generally, the ratio of $\frac{\sigma_{l}^{i}}{\sigma_{c}^{i}}$ indicates, which of the two input variables into the utility function, consumption or labor, causes a larger change in marginal utility. If marginal utility reacts a lot to changes in labor supply $\frac{d y_{i}}{y_{i}}$, then it is optimal for the household to rather increase consumption than labor in response to a change in exogenous income so as to keep the intratemporal first-order condition balanced.

In addition to the above elasticities, the relation between period 1 and period 2 labor earnings in equation (19) depends on two additional elasticities. On the one hand, there are elasticities related to the curvature of the utility function at different ages

$$
\epsilon_{c}^{i}=\frac{u_{c c}^{i} c_{i}}{u_{c}^{i}}
$$

Those elasticities define the intertemporal elasticity of substitution between consumption at different ages

$$
E_{c_{2} c_{1}}=\frac{d \log \left(\frac{c_{2}}{c_{1}}\right)}{d \log \left(\frac{u_{c}^{2}}{u_{c}^{1}}\right)}=\frac{\frac{d c_{2}}{c_{2}}-\frac{d c_{1}}{c_{1}}}{\epsilon_{c}^{2} \frac{d c_{2}}{c_{2}}-\epsilon_{c} \frac{d c_{1}}{c_{1}}} .
$$

The other relevant elasticity is the Frisch elasticity of labor supply with respect to a change in wages, respectively it's inverse,

$$
v_{l}^{i}=\frac{1}{\left.\frac{d \log \left(l_{i}\right)}{d \log \left(w_{i}\right)}\right|_{\lambda_{i}=\text { const. }}}=\frac{u_{l l}^{i} l_{i}}{u_{l}^{i}}-\frac{\left(u_{c l}^{i}\right)^{2} l_{i}}{u_{c c}^{i} u_{l}^{i}}
$$

where $\lambda_{i}$ is the Lagrangean multiplier on the period $i$ budget constraint of the dynamic household optimization problem. 
Bringing those concepts together, we can finally write

$$
\frac{d y_{2}}{y_{2}}=\frac{\epsilon_{c}^{1} / \sigma_{c}^{1}}{\epsilon_{c}^{2} / \sigma_{c}^{2}} \frac{v_{l}^{1}}{v_{l}^{2}} \frac{d y_{1}}{y_{1}}
$$

Again, a similar intuition than before applies:

1. The ratio $\frac{\epsilon_{c}^{i}}{\sigma_{c}^{i}}$ can be interpreted as an indicator for how much marginal utility of consumption in period $i$ reacts to changes in labor earnings $\frac{d y_{i}}{y_{i}}$ in this very period. If, for the same relative change in labor earnings, period 1 marginal utility of consumption would react much more than period 2 marginal utility, meaning $\frac{\epsilon_{c}^{1}}{\sigma_{c}^{1}}>\frac{\epsilon_{c}^{2}}{\sigma_{c}^{2}}$, then it is the optimal choice for the household to rather adjust $y_{2}$ and not $y_{1}$.

2. The same intuition applies to the ratio of the inverses of the Frisch elasticities. If $\frac{v_{l}^{1}}{v_{1}^{2}}$ is large, this essentially means that marginal utility of labor moves quickly with changes in labor supply in period 1 , and not so fast in period 2 . Hence, it is again optimal to rather adjust $y_{2}$ instead of $y_{1}$ to a change in exogenous income.

\section{The present value of labor earnings}

We now want to move towards clarifying what happens to the present value of labor earnings in response to an increase in unearned income. To this end, we differentiate the budget constraint and obtain

$$
c_{1} \frac{d c_{1}}{c_{1}}+\frac{c_{2}}{1+r} \frac{d c_{2}}{c_{2}}=(1-\tau) y_{1} \frac{d y_{1}}{y_{1}}+\frac{(1-\tau) y_{2}}{1+r} \frac{d y_{2}}{y_{2}}+d R .
$$

Plugging in (20) yields

$$
\left[(1-\tau) y_{1}-c_{1} \frac{\sigma_{l}^{1}}{\sigma_{c}^{1}}\right] \frac{d y_{1}}{y_{1}}+\frac{(1-\tau) y_{2}-c_{2} \frac{\sigma_{l}^{2}}{\sigma_{c}^{2}}}{1+r} \frac{d y_{2}}{y_{2}}=-d R .
$$

Using (21) then leads to

$$
\left\{\left[(1-\tau) y_{1}-c_{1} \frac{\sigma_{l}^{1}}{\sigma_{c}^{1}}\right]+\frac{(1-\tau) y_{2}-c_{2} \frac{\sigma_{l}^{2}}{\sigma_{c}^{2}}}{1+r} \frac{\epsilon_{c}^{1} / \sigma_{c}^{1}}{\epsilon_{c}^{2} / \sigma_{c}^{2}} \frac{v_{l}^{1}}{v_{l}^{2}}\right\} \frac{d y_{1}}{y_{1}}=-d R
$$

from which we obtain

$$
\frac{d y_{1} / y_{1}}{d R}=-\frac{\epsilon_{c}^{2} v_{l}^{2} \sigma_{c}^{1}}{\epsilon_{c}^{2} v_{l}^{2}\left[(1-\tau) y_{1} \sigma_{c}^{1}-c_{1} \sigma_{l}^{1}\right]+\epsilon_{c}^{1} v_{l}^{1} \frac{(1-\tau) y_{2} \sigma_{c}^{2}-c_{2} \sigma_{l}^{2}}{1+r}}
$$


For the present value of labor earnings, we then immediately obtain

$$
\begin{aligned}
\frac{d y_{1}+\frac{d y_{2}}{1+r}}{d R} & =-\frac{\epsilon_{c}^{2} v_{l}^{2} \sigma_{c}^{1} y_{1}+\epsilon_{c}^{1} v_{l}^{1} \sigma_{c}^{2} \frac{y_{2}}{1+r}}{\epsilon_{c}^{2} v_{l}^{2}\left[(1-\tau) y_{1} \sigma_{c}^{1}-c_{1} \sigma_{l}^{1}\right]+\epsilon_{c}^{1} v_{l}^{1} \frac{(1-\tau) y_{2} \sigma_{c}^{2}-c_{2} \sigma_{l}^{2}}{1+r}} \\
& =-\frac{1}{(1-\tau)\left[1-\frac{\epsilon_{c}^{2} v_{l}^{2} \sigma_{l}^{1} c_{1}+\epsilon_{c}^{1} v_{l}^{1} \sigma_{l}^{2} \frac{c_{2}}{1+r}}{\epsilon_{c}^{2} v_{l}^{2} \sigma_{c}^{1}(1-\tau) y_{1}+\epsilon_{c}^{1} v_{l}^{1} \sigma_{c}^{2} \frac{(1-\tau) y_{2}}{1+r}}\right]} .
\end{aligned}
$$

From equation (22), we can see that the reaction in the present value of labor supply is governed by two components, the net-of-tax rate $1-\tau$ as well as an allocation weighted ratio of elasticities. If the elasticity term was equal to zero, this would correspond to the situation where all the effect from a change in exogenous income goes into labor supply and the present value of consumption stays constant. In this case, the household can lower the present value of labor earnings by a factor $\frac{d R}{1-\tau}$ to keep the present value of earned plus unearned income constant. Yet, if both leisure (the complement to labor) and consumption are strictly normal goods, then we would expect the earnings reaction to be smaller than $-\frac{d R}{1-\tau}$. The elasticity term then governs exactly how much of the income effect of the change in exogenous income is absorbed by consumption and how much by labor supply. Note that in the case of strictly normal goods, we should expect $\frac{\sigma_{l}^{i}}{\sigma_{c}^{i}}<0$, hence,

$$
1-\frac{\epsilon_{c}^{2} v_{l}^{2} \sigma_{l}^{1} c_{1}+\epsilon_{c}^{1} v_{l}^{1} \sigma_{l}^{2} \frac{c_{2}}{1+r}}{\epsilon_{c}^{2} v_{l}^{2} \sigma_{c}^{1}(1-\tau) y_{1}+\epsilon_{c}^{1} v_{l}^{1} \sigma_{c}^{2} \frac{(1-\tau) y_{2}}{1+r}}>1
$$

\section{The present value of labor earnings and the discount factor}

Note that in (22) it looks like the change in the present value of labor earnings is in fact independent of the discount factor $\beta$. Yet, we have to recall that the elasticities in the elasticity ratio are weighted by the respective allocations $c_{1}, c_{2}$ as well as $y_{1}$ and $y_{2}$. Hence, if elasticities vary over the life cycle, a change in the discount factor $\beta$ will change the ratios $\frac{c_{1}}{c_{2}}$ and $\frac{y_{1}}{y_{2}}$ and therefore might also alter the present value reaction in labor earnings.

If the elasticities are time invariant, however, we can write

$$
\begin{aligned}
\frac{d y_{1}+\frac{d y_{2}}{1+r}}{d R} & =-\frac{1}{(1-\tau)\left[1-\frac{\sigma_{l}}{\sigma_{c}} \frac{c_{1}+\frac{c_{2}}{1+r}}{\left.(1-\tau) y_{1}+\frac{(1-\tau) y_{2}}{1+r}\right]}\right.} \\
& =-\frac{1}{(1-\tau)\left[1-\frac{\sigma_{l}}{\sigma_{c}}\right]-\frac{\sigma_{l}}{\sigma_{c}} \frac{R}{y}} \quad \text { with } \quad y=y_{1}+\frac{y_{2}}{1+r} .
\end{aligned}
$$

In this case, we obtain the same formulation as in Proposition 1. In particular, for our 
choice of preferences, we have

$$
\sigma_{l}=\frac{u_{l l} \cdot l}{u_{l}}=\chi \quad \text { and } \quad \sigma_{c}=\frac{u_{c c} \cdot c}{u_{c}}=-\gamma,
$$

which then immediately leads to

$$
\frac{d y}{d R}=-\frac{1}{\left(1+\frac{\chi}{\gamma}\right)(1-\tau)+\frac{\chi}{\gamma} \frac{R}{y}}
$$

\section{A.4 Anticipation Effects: Inheritances vs. Lottery Wins}

\section{Derivation of Equation (5)}

Households maximize

$$
\begin{aligned}
\frac{c_{0}^{1-\gamma}}{1-\gamma}-\frac{l_{0}^{1+\chi}}{1+\chi}+\beta[ & \pi\left(\frac{\left(c_{1}^{I}\right)^{1-\gamma}}{1-\gamma}-\frac{\left(l_{1}^{I}\right)^{1+\chi}}{1+\chi}+\beta \frac{\left(c_{2}^{I}\right)^{1-\gamma}}{1-\gamma}-\beta \frac{\left(l_{2}^{I}\right)^{1+\chi}}{1+\chi}\right) \\
& \left.+(1-\pi)\left(\frac{\left(c_{1}^{N}\right)^{1-\gamma}}{1-\gamma}-\frac{\left(l_{1}^{N}\right)^{1+\chi}}{1+\chi}+\beta \frac{\left(c_{2}^{N}\right)^{1-\gamma}}{1-\gamma}-\beta \frac{\left(l_{2}^{N}\right)^{1+\chi}}{1+\chi}\right)\right]
\end{aligned}
$$

subject to the constraints

$$
c_{0} \leq(1-\tau) y_{0}+T_{0}-a_{1}
$$

and

$$
c_{1}^{K}+\frac{c_{2}^{K}}{1+r} \leq(1-\tau)\left[y_{1}^{K}+\frac{y_{2}^{K}}{1+r}\right]+\mathbb{1}_{K=I}\left(1-\tau_{b}\right) b+T_{1}+\frac{T_{2}}{1+r}+(1+r) a_{1} .
$$

The relevant first order conditions are

$$
\begin{aligned}
& c_{0}=(1-\tau)^{\frac{1}{\chi}} w_{0}^{\frac{1+\chi}{\gamma}} y_{0}^{-\frac{\chi}{\gamma}} \\
& y_{0}=\left[\frac{w_{0}}{w_{1}}\right]^{1+\frac{1}{\chi}}[\beta(1+r)]^{\frac{1}{\chi}}\left[\pi\left(y_{1}^{I}\right)^{\chi}+(1-\pi)\left(y_{1}^{N}\right)^{\chi}\right]^{\frac{1}{\chi}} .
\end{aligned}
$$

Plugging equation (23) into the period 0 budget constraint, we obtain

$$
(1-\tau) y_{0}+R-(1-\tau)^{\frac{1}{\chi}} w_{0}^{\frac{1+\chi}{\gamma}} y_{0}^{-\frac{\chi}{\gamma}}=0,
$$

which by total differentiation immediately leads to equation (5). 


\section{Proof of Proposition 3}

We have

$$
R_{0}=T_{0}-a_{1} \quad \text { and } \quad R^{K}=\mathbb{1}_{K=I}\left(1-\tau_{b}\right) b+T_{1}+\frac{T_{2}}{1+r}+(1+r) a_{1}
$$

and therefore (assuming that lump-sum transfers are fixed) we obtain

$$
\frac{d R_{0}}{d \tau_{b}} \frac{1}{b}=-\frac{d a_{1}}{d \tau_{b}} \frac{1}{b} \quad \text { and } \quad \frac{d R^{K}}{d \tau_{b}} \frac{1}{b}=-\mathbb{1}_{K=I}+(1+r) \frac{d a_{1}}{d \tau_{b}} \frac{1}{b}
$$

The labor supply reactions can be calculated using by realizing that the chain rule implies

$$
\frac{d y_{0}}{d \tau_{b}} \frac{1}{b}=\frac{d y_{0}}{d R_{0}} \frac{d R_{0}}{d \tau_{b}} \frac{1}{b} \quad \text { and } \quad \frac{d y^{K}}{d \tau_{b}} \frac{1}{b}=\frac{d y^{K}}{d R^{K}} \frac{d R^{K}}{d \tau_{b}} \frac{1}{b}
$$

The present value reaction $\frac{d y}{d \tau_{b}} \frac{1}{b}$ follows immediately.

\section{The Savings Effect}

In order to calculate the effect of a bequest tax change on savings, we differentiate the intertemporal first order condition (24), which yields

$$
\begin{aligned}
d y_{0}= & {\left[\frac{w_{0}}{w_{1}}\right]^{1+\frac{1}{\chi}}[\beta(1+r)]^{\frac{1}{\chi}}\left[\pi\left(y_{1}^{I}\right)^{\chi}+(1-\pi)\left(y_{1}^{N}\right)^{\chi}\right]^{\frac{1}{\chi}-1} } \\
= & \underbrace{\left[\frac{w_{0}}{w_{1}}\right]^{1+\frac{1}{\chi}}\left[\beta\left(y_{1}^{I}\right)^{\chi-1} d y_{1}^{I}+(1-\pi)\left(y_{1}^{I}\right)^{\chi-1} d y_{1}^{N}\right\}}_{=y_{0}} \\
& \{\underbrace{\pi \frac{\left(y_{1}^{I}\right)^{\chi}}{\pi\left(y_{1}^{I}\right)^{\chi}+(1-\pi)\left(y_{1}^{N}\right) \chi}}_{=: \omega} \frac{d y_{1}^{I}}{y_{1}^{I}}+(1-\pi) \frac{\left.\left(y_{1}^{I}\right)^{\chi}+(1-\pi)\left(y_{1}^{N}\right)^{\chi}\right]^{\frac{1}{\chi}}}{\pi\left(y_{1}^{I}\right)^{\chi}+(1-\pi)\left(y_{1}^{N}\right) \chi} \frac{d y_{1}^{N}}{y_{1}^{N}}\} .
\end{aligned}
$$

From this, we immediately get

$$
\frac{d y_{0}}{y_{0}}=\omega \frac{d y_{1}^{I}}{y_{1}^{I}}+(1-\omega) \frac{d y_{1}^{N}}{y_{1}^{N}}
$$

Knowing that

$$
\frac{d y_{0}}{d \tau_{b}} \frac{1}{b}=-\eta_{0} \alpha \quad, \quad \frac{d y_{1}^{I}}{d \tau_{b}} \frac{1}{b}=\frac{\eta_{1}^{I}}{\Psi_{l}}[-1+(1+r) \alpha] \quad \text { and } \quad \frac{d y_{1}^{N}}{d \tau_{b}} \frac{1}{b}=\frac{\eta_{1}^{N}}{\Psi_{l}}(1+r) \frac{d a_{0}}{d \tau_{b}} \frac{1}{b},
$$


we can write

$$
\frac{\eta_{0}}{y_{0}} \alpha+\omega \frac{\eta_{1}^{I}}{\Psi_{l} y_{1}^{I}}[-1+(1+r) \alpha]+(1-\omega) \frac{\eta_{1}^{N}}{\Psi_{l} y_{1}^{N}}(1+r) \alpha=0
$$

from which follows that

$$
\alpha=\frac{\omega \frac{\eta_{1}^{I}}{y^{I}}}{\frac{\eta_{0}}{y_{0}}+\omega \frac{(1+r) \eta_{1}^{I}}{y^{I}}+(1-\omega) \frac{(1+r) \eta_{1}^{N}}{y^{N}}} \geq 0
$$

\section{B Wealth effect on labor earnings in quantitative model}

The dynamic household optimization problem in our model reads

$$
V_{t}\left(e, s, h_{t}, W_{t}\right)=\max _{c_{t}, l_{t}, a_{t+1}}\left\{\frac{c_{t}^{1-\gamma}}{1-\gamma}-\frac{l_{t}^{1+\chi}}{1+\chi}+\beta \mathbb{E}\left[V_{t+1}\left(e, s, h_{t+1}, W_{t+1}\right) \mid e, s, h_{t}\right]\right\}
$$

subject to the budget constraint

$$
c_{t}+a_{t+1}=w_{t}^{e} l_{t}-\mathcal{T}\left(w_{t}^{e} l_{t}\right)+\mathcal{P}_{t}^{e}+W_{t}
$$

where $\mathcal{P}_{t}^{e}=0$ for all workers. We can write the Lagrangean for a working age household as

$$
\mathcal{L}=\frac{c_{t}^{1-\gamma}}{1-\gamma}-\frac{l_{t}^{1+\chi}}{1+\chi}+\beta \mathbb{E}\left[V_{t+1}\left(e, s, h_{t+1}, W_{t+1}\right)\right]+\mu\left[w_{t}^{e} l_{t}-\mathcal{T}\left(w_{t}^{e} l_{t}\right)+W_{t}-c_{t}-a_{t+1}\right]
$$

Note that, in this setup, the choice variables as well as the Lagrangean multiplier are functions of the state variables. However, for ease of notation, we in the following only use an abbreviated notation without explicitly stating the state dependence of variables. First order conditions with respect to consumption and labor effort are

$$
\left(c_{t}\right)^{-\gamma}-\mu=0 \quad \text { and } \quad\left(y_{t}\right)^{\chi}=\mu\left[1-\mathcal{T}^{\prime}\left(y_{t}\right)\right]\left(w_{t}^{e}\right)^{1+\chi} .
$$

Together with the budget constraint, this leads to

$$
F\left(y_{t}, W_{t}, a_{t+1}\right):=\left(y_{t}\right)^{\chi}-\left[y_{t}-\mathcal{T}\left(y_{t}\right)+W_{t}-a_{t+1}\right]^{-\gamma}\left[1-\mathcal{T}^{\prime}\left(y_{t}\right)\right]\left(w_{t}^{e}\right)^{1+\chi}=0,
$$

which implicitly defines labor earnings. The implicit function theorem then implies

$$
\begin{gathered}
\frac{\partial F}{\partial y_{t}} d y_{t}+\frac{\partial F}{\partial W_{t}} d W_{t}+\frac{\partial F}{\partial a_{t+1}} d a_{t+1}=0 \\
\Leftrightarrow \quad\left[\chi\left(y_{t}\right)^{\chi-1}+\gamma\left(c_{t}\right)^{-\gamma-1}\left[1-\mathcal{T}^{\prime}\left(y_{t}\right)\right]^{2}\left(w_{t}^{e}\right)^{1+\chi}-\left(c_{t}\right)^{-\gamma}\left(-\mathcal{T}^{\prime \prime}\left(y_{t}\right)\right)\left(w_{t}^{e}\right)^{1+\chi}\right] d y_{t} \\
+\left[\gamma\left(c_{t}\right)^{-\gamma-1}\left[1-\mathcal{T}^{\prime}\left(y_{t}\right)\right]\left(w_{t}^{e}\right)^{1+\chi}\right] d W_{t}
\end{gathered}
$$




$$
\begin{gathered}
-\left[\gamma\left(c_{t}\right)^{-\gamma-1}\left[1-\mathcal{T}^{\prime}\left(y_{t}\right)\right]\left(w_{t}^{e}\right)^{1+\chi}\right] d a_{t+1}=0 \\
\Leftrightarrow \frac{\chi\left(y_{t}\right)^{\chi-1}+\gamma\left(c_{t}\right)^{-\gamma-1}\left[1-\mathcal{T}^{\prime}\left(y_{t}\right)\right]^{2}\left(w_{t}^{e}\right)^{1+\chi}+\left(c_{t}\right)^{-\gamma} \mathcal{T}^{\prime \prime}\left(y_{t}\right)\left(w_{t}^{e}\right)^{1+\chi}}{\gamma\left(c_{t}\right)^{-\gamma-1}\left[1-\mathcal{T}^{\prime}\left(y_{t}\right)\right]\left(w_{t}^{e}\right)^{1+\chi}} d y_{t} \\
=-d W_{t}\left[1-\frac{d a_{t+1}}{d W_{t}}\right] \\
\Leftrightarrow \quad\left[\frac{\chi}{\gamma} \frac{c_{t}}{y_{t}} \frac{\left(y_{t}\right)^{\chi}}{\left(c_{t}\right)^{-\gamma}\left[1-\mathcal{T}^{\prime}\left(y_{t}\right)\right]\left(w_{t}^{e}\right)^{1+\chi}}+1-\mathcal{T}^{\prime}\left(y_{t}\right)+\frac{c_{t}}{\gamma} \frac{\mathcal{T}^{\prime \prime}\left(y_{t}\right)}{1-\mathcal{T}^{\prime}\left(y_{t}\right)}\right] \frac{d y_{t}}{d w_{t}} \\
=-\left[1-\frac{d a_{t+1}}{d W_{t}}\right]
\end{gathered}
$$

From the first order conditions of the household problem, we directly get

$$
\frac{\left(y_{t}\right)^{\chi}}{\left(c_{t}\right)^{-\gamma}\left[1-\mathcal{T}^{\prime}\left(y_{t}\right)\right]\left(w_{t}^{e}\right)^{1+\chi}}=1
$$

Furthermore, using the functional form of our tax function yields

$$
1-\mathcal{T}^{\prime}\left(y_{t}\right)=\left(1-\tau_{1}\right) \frac{y_{t}-\mathcal{T}\left(y_{t}\right)}{y_{t}} \quad \text { and } \quad \frac{\mathcal{T}^{\prime \prime}\left(y_{t}\right)}{1-\mathcal{T}^{\prime}\left(y_{t}\right)}=-\frac{\tau_{1}}{y_{t}} .
$$

Hence, we obtain

$$
\frac{d y_{t}}{d W_{t}}=-\frac{1-\frac{d a_{t+1}}{d W_{t}}}{\frac{\chi+\tau_{1}}{\gamma} \frac{c_{t}}{y_{t}}+\left(1-\tau_{1}\right) \frac{y_{t}-\mathcal{T}\left(y_{t}\right)}{y_{t}}} .
$$

Plugging in the budget constraint for $c_{t}$ and rearranging terms gives the expression stated in the main text. 


\section{Calibration data extracted from GSOEP}

Table 6: Mean labor earnings in different earnings classes

\begin{tabular}{|c|c|c|c|c|c|c|c|c|}
\hline \multirow[b]{2}{*}{ Age } & \multicolumn{4}{|c|}{ Low Education } & \multicolumn{4}{|c|}{ High Education } \\
\hline & $e=1$ & $e=2$ & $e=3$ & $e=4$ & $e=5$ & $e=6$ & $e=7$ & $e=8$ \\
\hline $20-24$ & 3,126 & 8,947 & 16,061 & 31,182 & 2,676 & 9,070 & 19,407 & 36,026 \\
\hline $25-29$ & 6,342 & 16,614 & 26,748 & 42,639 & 7,274 & 21,607 & 35,064 & 55,638 \\
\hline $30-34$ & 11,544 & 23,854 & 32,762 & 50,884 & 18,828 & 34,868 & 46,228 & 73,596 \\
\hline $35-39$ & 13,965 & 26,082 & 34,988 & 52,340 & 22,071 & 38,341 & 50,761 & 81,618 \\
\hline $40-44$ & 15,216 & 27,946 & 37,049 & 56,708 & 22,313 & 39,453 & 53,004 & 89,428 \\
\hline $45-49$ & 14,184 & 27,929 & 38,173 & 59,408 & 22,582 & 40,171 & 54,511 & 94,091 \\
\hline $50-54$ & 12,547 & 26,578 & 37,469 & 60,999 & 21,083 & 40,803 & 56,316 & 98,965 \\
\hline $55-59$ & 10,328 & 22,015 & 33,568 & 58,279 & 15,927 & 36,203 & 53,249 & 96,778 \\
\hline $60-64$ & 9,002 & 15,500 & 23,521 & 45,613 & 12,640 & 26,474 & 42,283 & 76,568 \\
\hline $65+$ & 8,527 & 13,122 & 16,634 & 28,023 & 10,756 & 16,888 & 22,562 & 45,823 \\
\hline Share & 0.179 & 0.179 & 0.179 & 0.179 & 0.071 & 0.071 & 0.071 & 0.071 \\
\hline
\end{tabular}


Table 7: Fraction of heirs and mean bequest level by earnings class (low education)

\begin{tabular}{|c|c|c|c|c|c|c|}
\hline Age & $\begin{array}{l}\text { Frac. Heirs } \\
\quad \text { (in \%) }\end{array}$ & $\begin{array}{c}\text { Number } \\
\text { Heirs }\end{array}$ & $\begin{array}{c}\text { Mean } \\
\text { Bequest }\end{array}$ & $\begin{array}{c}\text { Frac. Heirs } \\
\quad \text { (in \%) }\end{array}$ & $\begin{array}{c}\text { Number } \\
\text { Heirs }\end{array}$ & $\begin{array}{c}\text { Mean } \\
\text { Bequest }\end{array}$ \\
\hline & \multicolumn{3}{|c|}{$e=1$} & \multicolumn{3}{|c|}{$e=2$} \\
\hline $20-34$ & $\begin{array}{c}0.84 \\
(0.14)\end{array}$ & 30 & $\begin{array}{c}26,579 \\
(9,659)\end{array}$ & $\begin{array}{c}0.61 \\
(0.11)\end{array}$ & 38 & $\begin{array}{c}53,812 \\
(16,780)\end{array}$ \\
\hline $35-44$ & $\begin{array}{c}0.81 \\
(0.13)\end{array}$ & 41 & $\begin{array}{c}39,176 \\
(10,543)\end{array}$ & $\begin{array}{c}1.19 \\
(0.15)\end{array}$ & 47 & $\begin{array}{c}31,761 \\
(6,165)\end{array}$ \\
\hline $45-54$ & $\begin{array}{c}1.11 \\
(0.15)\end{array}$ & 40 & $\begin{array}{c}68,150 \\
(15,992)\end{array}$ & $\begin{array}{l}1.08 \\
(0.15)\end{array}$ & 56 & $\begin{array}{l}49,147 \\
(8,699)\end{array}$ \\
\hline $55-64$ & $\begin{array}{c}1.25 \\
(0.18)\end{array}$ & 60 & $\begin{array}{c}52,864 \\
(10,495)\end{array}$ & $\begin{array}{l}1.17 \\
(0.16)\end{array}$ & 57 & $\begin{array}{l}51,501 \\
(8,282)\end{array}$ \\
\hline \multirow[t]{2}{*}{$65+$} & $\begin{array}{c}0.60 \\
(0.09)\end{array}$ & 41 & $\begin{array}{l}46,869 \\
(9,562)\end{array}$ & $\begin{array}{c}0.52 \\
(0.08)\end{array}$ & 41 & $\begin{array}{c}46,197 \\
(11,311)\end{array}$ \\
\hline & \multicolumn{3}{|c|}{$e=3$} & \multicolumn{3}{|c|}{$e=4$} \\
\hline $20-34$ & $\begin{array}{c}1.43 \\
(0.17)\end{array}$ & 47 & $\begin{array}{l}23,577 \\
(5,573)\end{array}$ & $\begin{array}{c}1.20 \\
(0.16)\end{array}$ & 51 & $\begin{array}{c}73,607 \\
(18,286)\end{array}$ \\
\hline $35-44$ & $\begin{array}{c}0.92 \\
(0.14)\end{array}$ & 49 & $\begin{array}{c}73,587 \\
(20,388)\end{array}$ & $\begin{array}{c}1.37 \\
(0.16)\end{array}$ & 71 & $\begin{array}{c}52,417 \\
(15,080)\end{array}$ \\
\hline $45-54$ & $\begin{array}{c}1.89 \\
(0.19)\end{array}$ & 95 & $\begin{array}{c}63,092 \\
(18,833)\end{array}$ & $\begin{array}{l}1.92 \\
(0.17)\end{array}$ & 131 & $\begin{array}{c}131,542 \\
(26,858)\end{array}$ \\
\hline $55-64$ & $\begin{array}{c}1.54 \\
(0.18)\end{array}$ & 73 & $\begin{array}{c}93,182 \\
(16,922)\end{array}$ & $\begin{array}{c}2.51 \\
(0.21)\end{array}$ & 136 & $\begin{array}{c}70,160 \\
(10,216)\end{array}$ \\
\hline $65+$ & $\begin{array}{c}0.58 \\
(0.09)\end{array}$ & 52 & $\begin{array}{c}47,055 \\
(9,451)\end{array}$ & $\begin{array}{l}1.04 \\
(0.11)\end{array}$ & 85 & $\begin{array}{c}62,391 \\
(17,901)\end{array}$ \\
\hline
\end{tabular}

Standard errors are reported in parenthesis. 
Table 8: Fraction of heirs and mean bequest level by earnings class (high education)

\begin{tabular}{|c|c|c|c|c|c|c|}
\hline Age & $\begin{array}{l}\text { Frac. Heirs } \\
\quad \text { (in \%) }\end{array}$ & $\begin{array}{c}\text { Number } \\
\text { Heirs }\end{array}$ & $\begin{array}{l}\text { Mean } \\
\text { Bequest }\end{array}$ & $\begin{array}{c}\text { Frac. Heirs } \\
\quad \text { (in \%) }\end{array}$ & $\begin{array}{c}\text { Number } \\
\text { Heirs }\end{array}$ & $\begin{array}{c}\text { Mean } \\
\text { Bequest }\end{array}$ \\
\hline & \multicolumn{3}{|c|}{$e=5$} & \multicolumn{3}{|c|}{$e=6$} \\
\hline $20-34$ & $\begin{array}{c}1.73 \\
(0.34)\end{array}$ & 23 & $\begin{array}{c}72,007 \\
(28,507)\end{array}$ & $\begin{array}{l}1.14 \\
(0.26)\end{array}$ & 21 & $\begin{array}{c}33,552 \\
(10,246)\end{array}$ \\
\hline $35-44$ & $\begin{array}{c}0.81 \\
(0.18)\end{array}$ & 21 & $\begin{array}{c}46,598 \\
(16,519)\end{array}$ & $\begin{array}{c}1.22 \\
(0.21)\end{array}$ & 32 & $\begin{array}{c}35,946 \\
(9,806)\end{array}$ \\
\hline $45-54$ & $\begin{array}{c}2.38 \\
(0.31)\end{array}$ & 52 & $\begin{array}{c}54,616 \\
(10,300)\end{array}$ & $\begin{array}{l}1.67 \\
(0.24)\end{array}$ & 55 & $\begin{array}{c}68,809 \\
(18,128)\end{array}$ \\
\hline $55-64$ & $\begin{array}{c}2.04 \\
(0.31)\end{array}$ & 41 & $\begin{array}{c}55,539 \\
(12,675)\end{array}$ & $\begin{array}{l}3.11 \\
(0.36)\end{array}$ & 65 & $\begin{array}{c}94,364 \\
(16,702)\end{array}$ \\
\hline \multirow[t]{2}{*}{$65+$} & $\begin{array}{c}1.13 \\
(0.21)\end{array}$ & 36 & $\begin{array}{c}69,136 \\
(15,121)\end{array}$ & $\begin{array}{c}0.88 \\
(0.17)\end{array}$ & 27 & $\begin{array}{c}103,915 \\
(26,950)\end{array}$ \\
\hline & \multicolumn{3}{|c|}{$e=7$} & \multicolumn{3}{|c|}{$e=8$} \\
\hline $20-34$ & $\begin{array}{c}2.03 \\
(0.36)\end{array}$ & 30 & $\begin{array}{c}281,532 \\
(107,188)\end{array}$ & $\begin{array}{c}2.05 \\
(0.38)\end{array}$ & 25 & $\begin{array}{c}81,609 \\
(22,610)\end{array}$ \\
\hline $35-44$ & $\begin{array}{c}1.47 \\
(0.23)\end{array}$ & 41 & $\begin{array}{l}31,910 \\
(5,146)\end{array}$ & $\begin{array}{l}1.85 \\
(0.25)\end{array}$ & 56 & $\begin{array}{c}95,899 \\
(16,113)\end{array}$ \\
\hline $45-54$ & $\begin{array}{c}2.68 \\
(0.28)\end{array}$ & 79 & $\begin{array}{c}55,250 \\
(11,426)\end{array}$ & $\begin{array}{c}2.50 \\
(0.25)\end{array}$ & 114 & $\begin{array}{c}112,098 \\
(24,719)\end{array}$ \\
\hline $55-64$ & $\begin{array}{c}2.75 \\
(0.33)\end{array}$ & 85 & $\begin{array}{c}97,200 \\
(16,277)\end{array}$ & $\begin{array}{c}3.87 \\
(0.33)\end{array}$ & 152 & $\begin{array}{l}127,256 \\
(38,036)\end{array}$ \\
\hline $65+$ & $\begin{array}{c}2.33 \\
(0.28)\end{array}$ & 61 & $\begin{array}{c}76,044 \\
(12,190)\end{array}$ & $\begin{array}{c}2.52 \\
(0.27)\end{array}$ & 92 & $\begin{array}{c}133,747 \\
(22,585)\end{array}$ \\
\hline
\end{tabular}

Standard errors are reported in parenthesis. 


\section{Details on the Calibration of Labor Productivity and Labor Supply}

In this appendix, we describe how we use the estimated labor earnings profiles we obtained from the GSOEP in order to parameterize the life-cycle labor productivity profiles of households. Note that, in our model, labor productivity is assumed to be deterministic over the life cycle and utility from consumption and disutility from labor are additively separable. In order to be able to apply the strategy of Saez (2001), we have to make one additional simplifying assumption, namely that instead of receiving bequests according to the risk process outlined above, households of each earnings class $e$ receive a lump-sum transfer in each period of life that is equal to the average amount of bequest for this group, that is

$$
\mathcal{Z}_{t}^{e}=p_{t}^{e} \sum_{i=0}^{n} \omega_{i}^{e} b_{i t}^{e}
$$

In doing so, we eliminate all uncertainty from our model, ${ }^{23}$ which allows us to write the household optimization problem as

$$
\begin{aligned}
& \max _{c_{t}^{e}, y_{t}^{e}, a_{t+1}^{e}} \sum_{t=1}^{T} \beta^{t-1}\left(\frac{\left(c_{t}^{e}\right)^{1-\gamma}}{1-\gamma}-\frac{\left[\frac{y_{t}^{e}}{w_{t}^{e}}\right]^{1+\chi}}{1+\chi}\right) \\
& \text { s.t. } \quad c_{t}^{e}+a_{t+1}^{e}=y_{t}^{e}-\mathcal{T}\left(y_{t}^{e}\right)+\mathcal{P}_{t}^{e}+\mathcal{Z}_{t}^{e}+(1+r) a_{t}^{e} \text { and } a_{t+1}^{e} \geq a_{\text {min }} .
\end{aligned}
$$

The first order conditions of this problem read

$$
\begin{aligned}
\left(c_{t}^{e}\right)^{-\gamma} & =\beta(1+r)\left(c_{t+1}^{e}\right)^{-\gamma}+\alpha_{t} \quad \text { with } a_{t+1} \alpha_{t}=0 \quad \text { and } \\
\left(w_{t}^{e}\right)^{1+\chi} & =\frac{1}{1-\mathcal{T}^{\prime}\left(y_{t}^{e}\right)} \frac{\left(y_{t}^{e}\right)^{\chi}}{\left(c_{t}^{e}\right)^{-\gamma}}
\end{aligned}
$$

where $\alpha_{t}$ is the Lagrangian multiplier on the minimum asset constraint in instantaneous utility values. Given a government policy $\mathcal{T}(\cdot)$ and $\mathcal{P}_{t}^{e}$, a set of lump sum transfers $\mathcal{Z}_{t}^{e}$ and a deterministic earnings path $y_{t}^{e}$, we can use the Euler equation together with the household budget constraint to calculate the deterministic consumption path $c_{t}^{e}$. We can then use the intra-period first order condition to back out the corresponding labor productivity profile $w_{t}^{e}$ for households of earnings class $e$. Note that the resulting productivity profile is only approximately correct, owing to the assumption we made. However, comparing the model simulated average earnings path including bequest uncertainty for each earnings class to the earnings profiles estimated from the data showed only minor differences.

23 Note that we only do this for the purpose of calibration, not in our main simulations. 


\section{E Details on the Income Tax Approximation}

This section provides details on the approximation of the income tax schedule depicted in Figure 4 of the main text. The left panel of this figure shows a very close fit in the mapping of gross to net labor income, implying a good approximation of average tax rates along the whole income distribution. At the same time, however, the right panel of the same figure reveals stronger discrepancies between the approximated marginal income tax schedule and the actual one. As for marginal responses in labor income, the marginal tax rate is relevant for the change in government revenues, these discrepancies might potentially bias our results. In this section, we argue that such a bias is small and, if anything, accounting for it would slightly increase our number of interest.

Figure 8: Marginal Tax Rates along the Lifecycle
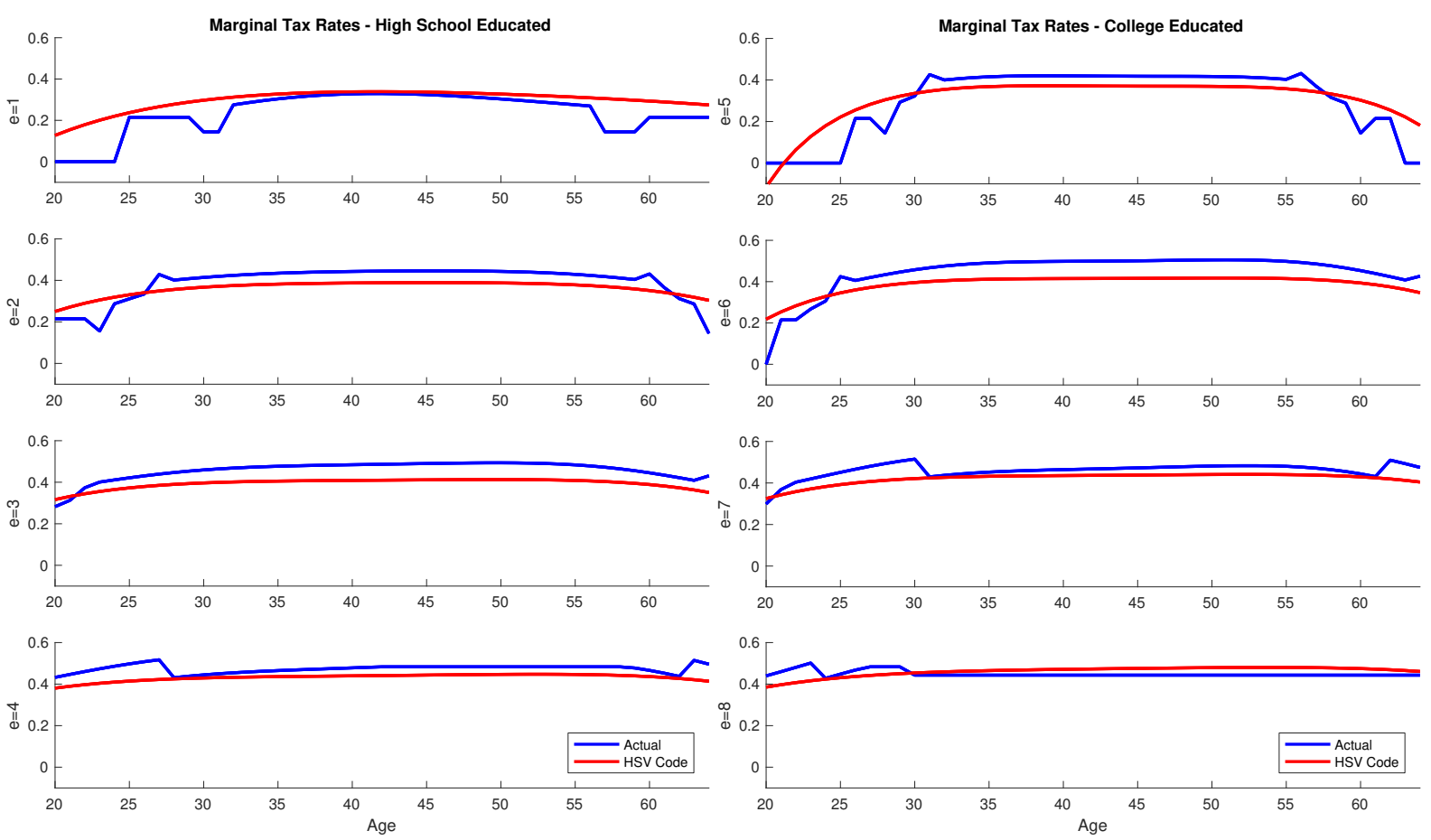

For this means we depict the actual vs. approximated marginal income tax rates over the whole working-life-cycle for our eight different earnings categories in Figure $8 .{ }^{24}$ The figure shows that along the whole life-cycle agents in earnings categories

24 To be precise, the Figure shows the marginal tax rates for the average earner across all heirs and non-heirs in each earnings category. In principle, agents' earnings depend on the age at which they learn about their inheritance (46 possibilities: 45 working years plus anytime during retirement), their expected inheritance class (5 possibilities), and their actual inheritance class (5 possibilities), amounting to a total of 9,200 instead of eight earnings profiles. However, within each earnings category the differences in labor earnings are very small. 
$e \in\{2,4,5,7,8\}$ pay, on average, approximately the same marginal tax rates in the model as they would in reality. The fit is less good for the lowest earnings category, where tax rates in the model are constantly above actual ones as well as for categories 3 and 6, where model tax rates are, except for the very early years, constantly below the actual ones.

Table 9 summarizes for each earnings category the mean marginal tax rates over the life-cycle both in the model and in reality. The last row shows by how much the actual marginal tax rate differs from the one in the model, in relative terms. These numbers can be seen as upper bounds for the bias we introduce by using the smooth tax schedule. ${ }^{25}$ In particular, if agents' behavior was fixed, the numbers in the last row would tell us by how much we over- or underestimate the response in labor income tax revenue. Taking into account that with higher (lower) tax rates, agents would work less (more), the biases would be lower, whatever the direction is.

Table 9: Mean marginal tax rates over the lifecycle

\begin{tabular}{|c|c|c|c|c|c|c|c|c|}
\hline \multirow[b]{2}{*}{$e=$} & \multicolumn{4}{|c|}{ Low Education } & \multicolumn{4}{|c|}{ High Education } \\
\hline & 1 & 2 & 3 & 4 & 5 & 6 & 7 & 8 \\
\hline Model & 29.6 & 36.2 & 39.4 & 43.2 & 30.5 & 38.8 & 42.2 & 46.1 \\
\hline Actual & 23.4 & 39.0 & 45.7 & 47.4 & 30.1 & 44.6 & 46.0 & 44.9 \\
\hline Rel. diff. & -21.0 & 7.9 & 16.1 & 9.7 & -1.2 & 14.9 & 9.2 & -2.7 \\
\hline
\end{tabular}

Tax rates in percentage points. Relative difference in percent of model tax rate.

But let us for the moment assume that the behavioral effect is null, and that these mechanical effects were an accurate description of the bias. We observe that only for the aforementioned earnings categories $e \in\{1,3,6\}$ the discrepancy is above $10 \%$ and only for the lowest earnings category do we significantly overestimate the response in labor earnings. The first row of table 10 repeats the results we documented in the main text (compare Table 4). In the second row, we compute the same numbers taking into account the bias (which, as we already mentioned can be seen as an upper bound for how much numbers would actually change). Only for earnings categories 3 and 6 do we observe that labor income tax revenue per Euro of bequest tax revenue, changes by more than one Cent. Moreover, for both of these categories, our model actually underpredicts government tax revenue. Although we overestimate tax revenues from the lowest earners by $21 \%$, this does not affect government revenues much, as from these agents the government is raising little revenue to begin with.

Furthermore, as can be seen by Figure 3 in the main text, bequests and earnings are

25 To be precise, in this exercise we assume for simplicity that labor supply responses to inheritance tax changes are equally spread over the working-life-cycle. That this is a very good approximation can be verified by multiplying the average tax rates in the first row of Table 9 with the earnings in the first row of Table 4 . The resulting numbers are very similar to the taxes in the second row of Table 4 . 
Table 10: Effect of a 1\% increase in bequest taxes by Earnings-Class

\begin{tabular}{|c|c|c|c|c|c|c|c|c|}
\hline \multirow[b]{2}{*}{$e=$} & \multicolumn{4}{|c|}{ Low Education } & \multicolumn{4}{|c|}{ High Education } \\
\hline & 1 & 2 & 3 & 4 & 5 & 6 & 7 & 8 \\
\hline Taxes & 4.57 & 7.52 & 8.47 & 10.34 & 5.65 & 8.01 & 9.87 & 11.19 \\
\hline wo bias & 3.61 & 8.11 & 9.82 & 11.34 & 5.58 & 9.20 & 10.78 & 10.88 \\
\hline
\end{tabular}

Revenue effects are measured as fraction of change in bequest tax revenue by earnings class.

positively correlated. Since the numbers reported in Table 10 are per Euro of bequest tax revenue raised, higher earners, who receive more bequests, enter with a higher weight when calculating the total number. For high earners our model tends to underpredict marginal tax rates. Accordingly, taking the biases above again at face value would imply that in total one Euro of bequest tax revenue raised, increases labor income tax revenue by 9.32 Cents instead of 8.87 Cents. In sum, given these results we are confident that our statement that each Euro of inheritance tax revenue leads to an increase in labor income tax revenue of around 9 Cents, is unaffected by the income tax approximation we apply.

\section{F Further Quantitative Results}

\section{F.1 The Short vs. the Long Run}

So far, we only focused on the effect of a change in the bequest tax rate on a cohort that has lived under the new bequest tax rate for their whole life. However, as already pointed out in the theoretical analysis, there is a difference between such cohorts and generations that are surprised by a change in bequest taxes at some date in the middle of their life cycle. In the following, we therefore conduct the same thought experiment as in our theoretical analysis. We assume that the economy is in a steady state with a bequest tax rate of $0 \%$. Then, the government surprisingly increases the bequest tax rate by one percentage point. Figure 9 then shows the excess labor tax effect on cohorts with different ages at the time of the reform. Of course, for the cohort aged 1, we again get the very same number as in previous sections, as this cohort is the one that lives under the new tax system for their whole life span.

The older a cohort is at the time the bequest tax rate changes, the less years of work remain to react to the tax change. Consequently, the excess labor tax effect declines in a cohort's age almost everywhere. Only for very young cohorts, we see a slight increase in excess tax revenue, which is due to a denominator effect. Since bequests are most likely to arrive at later ages, the labor earnings effect for cohorts between ages 20 and 30 at the time of the reform is almost identical. However, as some inheritances do 
Figure 9: Short-run vs. Long-run Effects

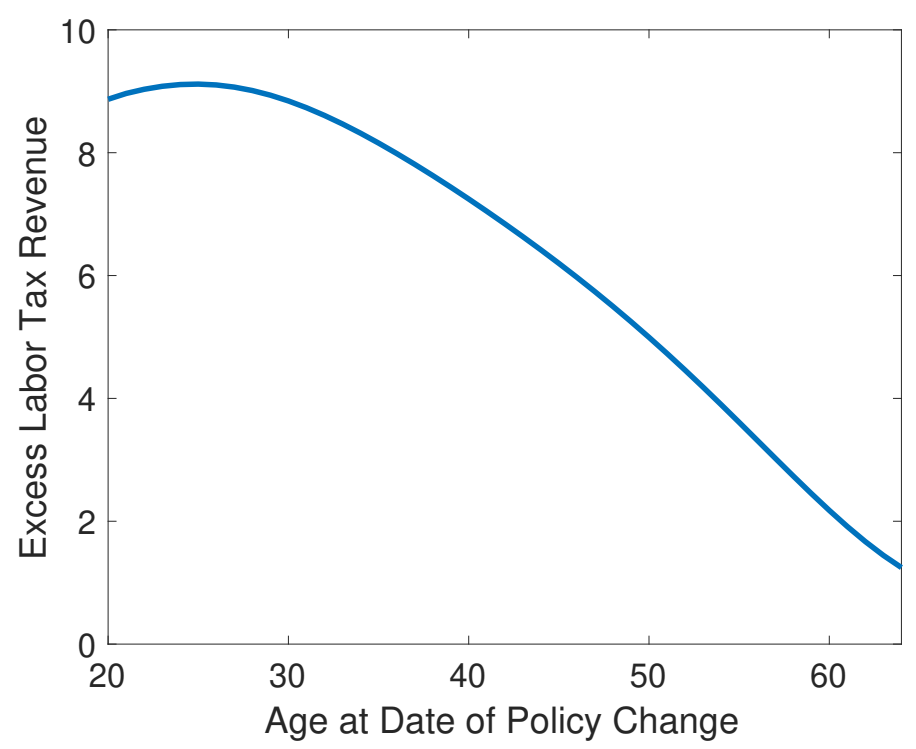

arrive at these ages, the present value of bequest tax revenue (the denominator in the excess tax revenue effect) decreases in age, which causes the overall excess labor tax effect to increase slightly.

\section{F.2 Sensitivity Analysis}

As discussed in section 5.3, we have three parameters - the coefficient of relative risk aversion $\gamma$, the inverse of the Frisch elasticity of labor supply $\chi$, and the discount factor $\beta$-in order to match two targets - the propensity to earn out of lottery gains in the five years following the lottery win, and the steepness of the impulse response function in labor earnings. Our benchmark calibration of $\gamma=1, \chi=4.06$, and $\beta=0.981$ implies that both risk aversion and the Frisch elasticity of labor supply are in the range of empirical estimates, even though both are at the lower end of this range. In this section we provide robustness checks to this choice. Specifically, we consider the case of a relatively high Frisch elasticity of $0.5(\chi=2.0)$. In order for the model to match the lottery evidence on labor earnings, this yet implies that risk aversion needs to be extremely low $(\gamma=0.51)$. Similarly, we consider the other extreme case of a high risk aversion $(\gamma=4.0)$, even though this implies an extremely low Frisch labor supply elasticity of $0.06(\chi=16.8)$ and a time discount factor $\beta>1$. For each of these calibrations, we compute the effect of a marginal increase in bequest taxes on labor earnings and excess labor income taxes. Table 11 summarizes the results.

Despite the very different parameterizations, our number of interest is affected only modestly in both cases. In the case of a high labor supply elasticity and very low risk aversion, it increases by a quarter of a cent to 9.13, while in the case of high risk aver- 
Table 11: Effect of a 1\% increase in bequest taxes

\begin{tabular}{lcccc}
\hline & \multicolumn{4}{c}{$\gamma=0.51, \chi=2.0$ and $\beta=0.9715$} \\
\cline { 2 - 5 } & Total & Anticipation & Heirs & Non-Heirs \\
\hline Gross Earnings & 22.32 & 11.41 & 11.64 & -0.73 \\
Labor Taxes & 9.13 & 4.59 & 4.83 & -0.29 \\
\hline & \multicolumn{5}{c}{$\gamma=4.0, \chi=16.8$ and $\beta=1.04$} \\
\cline { 2 - 5 } & Total & Anticipation & Heirs & Non-Heirs \\
\hline Gross Earnings & 18.86 & 6.65 & 12.61 & -0.40 \\
Labor Taxes & 7.76 & 2.69 & 5.24 & -0.16 \\
\hline
\end{tabular}

Effects are measured as fraction of change in bequest tax revenue.

sion and very low labor supply elasticity, it decreases by a bit more than one cent to 7.76. We further observe that for the parameterization with high risk aversion, anticipation effects are much smaller than with low-risk-aversion individuals. The reason for this is that highly risk averse household value the stochastic stream of (potential) future bequests much less than their low risk averse counterparts. Consequently, they are less willing to engage in consumption smoothing against this risky source of income.

\section{F.3 Larger Inheritance Tax Increases}

The result that each Euro of inheritance tax revenue mechanically raised increases labor income tax revenue by around nine Cents is by and large unaffected by the rate, at which inheritances are taxed. If anything, it increases in the tax rate as Figure 10 shows.

\section{F.4 Changes in Capital Income Tax Revenue}

In this section we discuss potential capital tax revenue effects when inheritance taxes are increased. The first row in Table 12 shows how the net present value of asset income changes after the reform in our benchmark calibration. Since only positive income is taxable we restricted the analysis to changes in interest income when the household has positive wealth. We observe that total (positive) asset income is reduced by 18 Cents per Euro of bequest tax revenue raised. The decomposition of this effect in anticipation and post-receipt effect is intuitive. Most action comes from a mechanical reduction in heirs' wealth, whose capital income is reduced by around 46 Cents. In anticipation of receiving lower (expected) net inheritances, agents save more prior to the receipt, leading to a positive anticipation effect of 26 Cents. As a consequence those agents, who end up not inheriting, have higher wealth at the time they learn this, with which 
Figure 10: Varying Inheritance Tax Rate

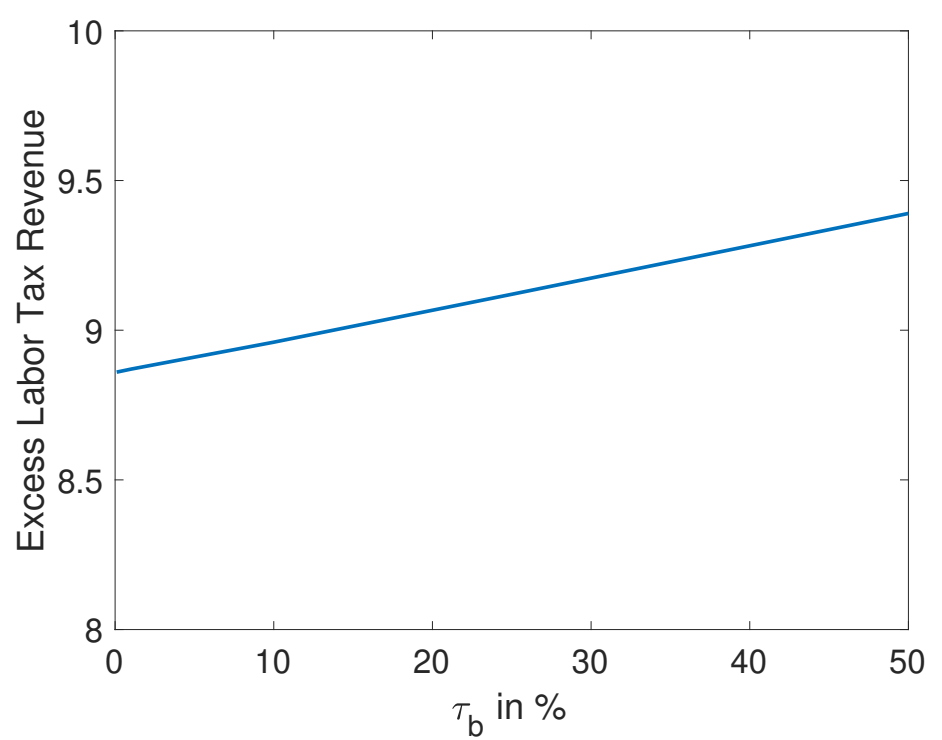

they generate higher interest income of about 2 Cents.

Table 12: Effect of a 1\% increase in bequest taxes

\begin{tabular}{lcccc}
\hline & & \multicolumn{3}{c}{ Decomposition } \\
\cline { 3 - 5 } & Total & Anticipation & Heirs & Non-Heirs \\
\hline Asset Inc. $(\geq 0)$ & -17.57 & 25.74 & -45.68 & 2.37 \\
Capital Taxes $(25 \%)$ & -4.39 & 6.44 & -11.42 & 0.59 \\
\hline
\end{tabular}

Effects are measured as fraction of change in bequest tax revenue

The second row of Table 12 would be the change in capital income tax revenue if all capital income was taxed at the statutory tax rate of $25 \%$. In this case the positive revenue effect from labor income taxes (8.9 Cents) would be reduced by almost half (-4.4 Cents) through lower capital income taxes.

However, there are several reasons why the true changes in capital income tax revenue are much smaller than that. First, in the first row above only positive asset income is accounted for. In practice one can partially - not fully and not over the whole lifetime offset capital gains with losses from previous years for tax purposes. Second, while in our model agents can only save in one asset, in practice German households' wealth is held in various assets, many of which are not subject to capital income taxation. According to data from the Bundesbank's Panel of Household Finances, only 17\% of German wealth is held in assets that are subject to capital income taxation. Assuming that marginal changes in asset holdings are spread in the same proportion over the different assets, this would reduce the capital income tax revenue loss to $0.17 \times 4.39=0.75$ 
Cents. Finally, even for assets that are subject to capital income taxes, there exists an exemption level in Germany of 800 Euro per year. As a consequence only 11\% of households actually pay capital income taxes. If the change in capital income was split evenly across households this would mean that the actual revenue change is only $0.11 \times 4.39=0.48$ Cents. These are, of course, simplified back-of-the-envelope calculations. Nevertheless, given these facts, it seems reasonable to assume that the reduction in capital income tax revenue is not more than $1 \%$ of the increase in bequest tax revenue (compared to an increase in labor income tax revenue of $9 \%$ ).

\section{F.5 Borrowing Limits}

In our benchmark calibration we assumed that $a_{\text {min }}=-\infty$, meaning that as long as a household can service her debt until she dies, she can run into debt as much as she wishes. In this section, we look at the other extreme case, in which no borrowing is allowed at all $\left(a_{\min }=0\right)$. We again fix the parameter $\gamma=1$ and re-calibrate $\chi$ and $\beta$ in order to replicate the empirical evidence on earnings responses of lottery winners (Cesarini et al., 2017). Specifically, we need to reduce $\chi$ to a value of 3.52 , leading to a Frisch elasticity of 0.28 (instead of 0.25 in our benchmark case), and increase the discount factor to $\beta=0.988$. Figure 11 again compares the average impulses of gross and net earnings in data and the model.

Figure 11: Impulse Response Functions in Data and Model with Strict Borrowing Limit
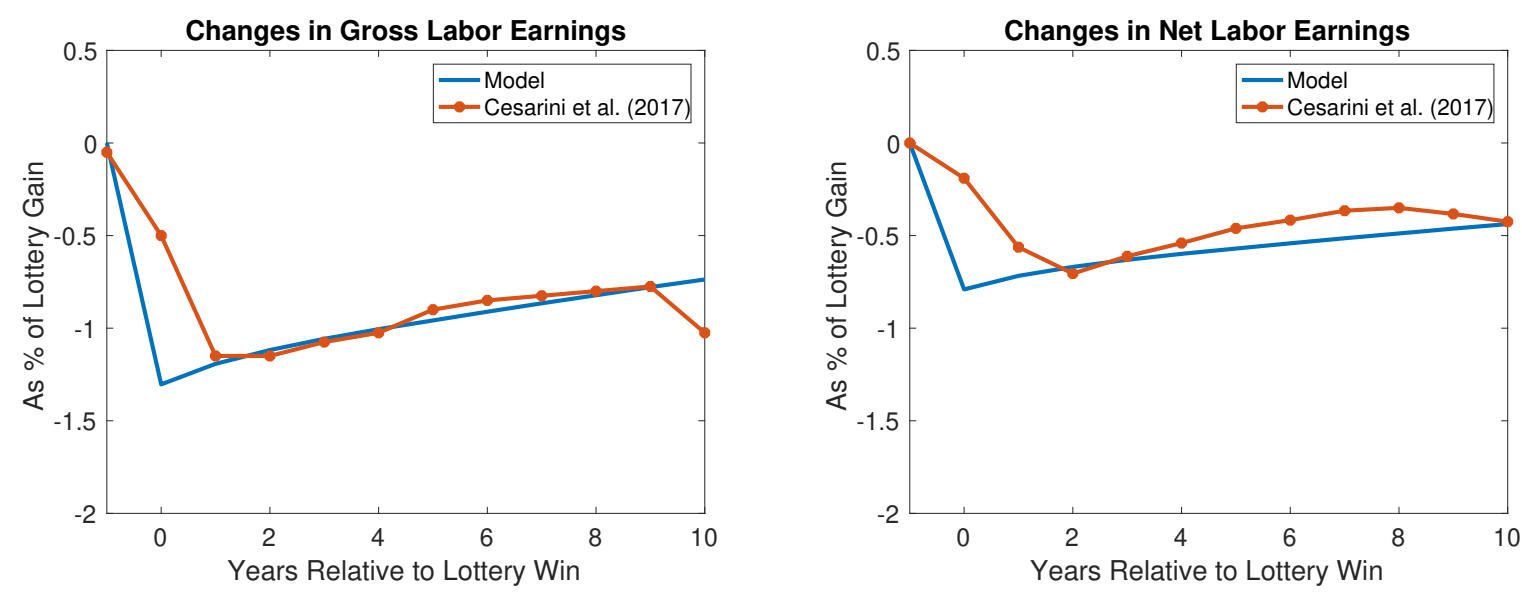

The results of our policy experiment (increasing the bequest tax from zero to $1 \%$ ) under this new calibration are presented in Table 13. Since the Frisch elasticity is now higher than in the benchmark scenario, both the labor supply and the labor tax reaction to a change in the bequest tax are more pronounced, with the tax effect being 10.3 cents instead of 8.9 cents. As before, anticipation and post-receipt effects are of similar magnitude. Figure 12 again depicts the changes in life-cycle profiles of savings and labor earnings for agents who inherit at age 50 . The strict no-borrowing limit makes it harder for agents to smooth consumption and labor supply over the life-cycle. While in the 
Table 13: Effect of a 1\% increase in bequest taxes, no borrowing

\begin{tabular}{lcccc}
\hline & \multicolumn{4}{c}{$\gamma=1.0, \chi=3.52$ and $\beta=0.988$} \\
\cline { 2 - 5 } & Total & Anticipation & Heirs & Non-Heirs \\
\hline Gross Earnings & 24.86 & 12.59 & 12.84 & -0.57 \\
Labor Taxes & 10.27 & 5.18 & 5.33 & -0.23 \\
\hline
\end{tabular}

Effects are measured as fraction of change in bequest tax revenue.

case of $a_{\min }=-\infty$ the increase in the bequest tax resulted in an increase of earnings and savings already from age 20 , now this is true only from age 25 onwards, at which the borrowing constraint stops binding.

Figure 12: Change in life-cycle behavior of different households
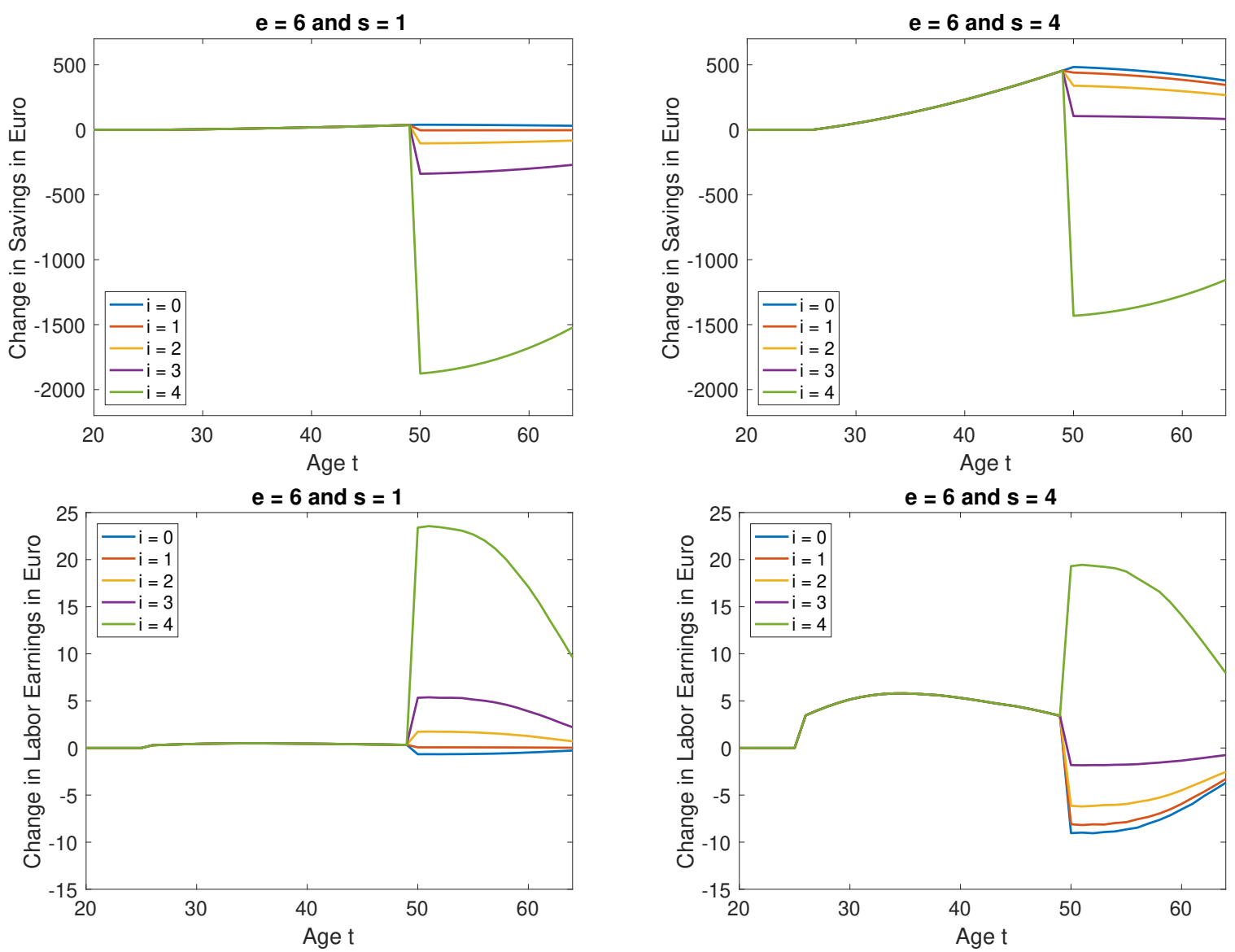

In sum, the analysis of this section suggests that our assumption of no exogenous borrowing limits leads to rather conservative estimates for the labor supply effects of bequest taxes. If borrowing limits actually play an important role in reality, our number of interest would be even larger than the 9 cents we obtained in our benchmark simulations. 